\title{
Magnetoliposomes Based on Magnetic/Plasmonic Nanoparticles Loaded with Tricyclic Lactones for Combined Cancer Therapy
}

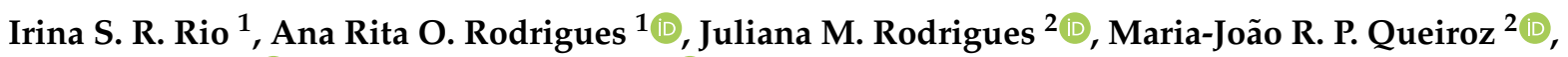 \\ R. C. Calhelha $\left.{ }^{3}{ }^{(}\right)$, Isabel C. F. R. Ferreira ${ }^{3}{ }^{-}$, Bernardo G. Almeida ${ }^{1}$, Ana Pires ${ }^{4}$, André M. Pereira ${ }^{4}$, \\ João P. Araújo ${ }^{4}{ }^{(\mathbb{D}}$, Elisabete M. S. Castanheira ${ }^{1, * \mathbb{C}}$ and Paulo J. G. Coutinho ${ }^{1, *(\mathbb{B})}$
}

check for updates

Citation: Rio, I.S.R.; Rodrigues, A.R.O.; Rodrigues, J.M.; Queiroz, M.-J.R.P.; Calhelha, R.C.; Ferreira, I.C.F.R.; Almeida, B.G.; Pires, A.; Pereira, A.M.; Araújo, J.P.; et al. Magnetoliposomes Based on Magnetic/Plasmonic Nanoparticles Loaded with Tricyclic Lactones for Combined Cancer Therapy. Pharmaceutics 2021, 13, 1905. https:// doi.org/10.3390/pharmaceutics13111905

Academic Editors: Juan

Aparicio-Blanco, Ana Isabel Torres-Suárez and Franco Dosio

Received: 1 September 2021 Accepted: 8 November 2021 Published: 10 November 2021

Publisher's Note: MDPI stays neutral with regard to jurisdictional claims in published maps and institutional affiliations.

Copyright: (c) 2021 by the authors. Licensee MDPI, Basel, Switzerland. This article is an open access article distributed under the terms and conditions of the Creative Commons Attribution (CC BY) license (https:// creativecommons.org/licenses/by/ $4.0 /)$.
1 Centre of Physics of Minho and Porto Universities (CF-UM-UP), University of Minho, Campus de Gualtar, 4710-057 Braga, Portugal; id9261@alunos.uminho.pt (I.S.R.R.); ritarodrigues@fisica.uminho.pt (A.R.O.R.); bernardo@fisica.uminho.pt (B.G.A.)

2 Centre of Chemistry (CQUM), University of Minho, Campus de Gualtar, 4710-057 Braga, Portugal; juliana.mourarodrigues@gmail.com (J.M.R.); mjrpq@quimica.uminho.pt (M.J.R.P.Q.)

3 Mountain Research Centre, Polytechnic Institute of Bragança, Campus de Santa Apolónia, 5300-253 Bragança, Portugal; calhelha@ipb.pt (R.C.C.); iferreira@ipb.pt (I.C.F.R.F.)

4 IFIMUP-Instituto de Física dos Materiais, Universidade do Porto, R. Campo Alegre, 4169-007 Porto, Portugal; ana.pires@fc.up.pt (A.P.); ampereira@fc.up.pt (A.M.P.); jearaujo@fc.up.pt (J.P.A.)

* Correspondence: ecoutinho@fisica.uminho.pt (E.M.S.C.); pcoutinho@fisica.uminho.pt (P.J.G.C.); Tel.: +351-253-604-321 (E.M.S.C. \& P.J.G.C.)

Abstract: Liposome-like nanoarchitectures containing manganese ferrite nanoparticles covered or decorated with gold were developed for application in dual cancer therapy, combining chemotherapy and photothermia. The magnetic/plasmonic nanoparticles were characterized using XRD, UV/Visible absorption, HR-TEM, and SQUID, exhibiting superparamagnetic behavior at room temperature. The average size of the gold-decorated nanoparticles was $26.7 \mathrm{~nm}$ for $\mathrm{MnFe}_{2} \mathrm{O}_{4}$ with 5-7 nm gold nanospheres. The average size of the core/shell nanoparticles was $28.8 \mathrm{~nm}$ for the magnetic core and around $4 \mathrm{~nm}$ for the gold shell. Two new potential antitumor fluorescent drugs, tricyclic lactones derivatives of thienopyridine, were loaded in these nanosystems with very high encapsulation efficiencies (higher than 98\%). Assays in human tumor cell lines demonstrate that the nanocarriers do not release the antitumor compounds in the absence of irradiation. Moreover, the nanosystems do not cause any effect on the growth of primary (non-tumor) cells (with or without irradiation). The drug-loaded systems containing the core/shell magnetic/plasmonic nanoparticles efficiently inhibit the growth of tumor cells when irradiated with red light, making them suitable for a triggered release promoted by irradiation.

Keywords: manganese ferrite/gold nanoparticles; magnetoliposomes; new antitumor drugs; thienopyridine derivatives; combined cancer therapy

\section{Introduction}

Cancer is a major public health problem, and the World Health Organization (WHO) points to it as the second leading cause of death worldwide. In 2018, nearly 9.6 million people died from several forms of cancer and in 2019, 1,762,450 new cancer cases were diagnosed and 606,880 deaths occurred in the United States. These numbers correspond to 4800 new cases and 1700 deaths per day [1]. One of the most prominent difficulties in cancer treatment is to achieve high concentrations of chemotherapeutic drugs in the malignant site while reducing nonspecific distribution throughout healthy tissues. In this regard, stimuli-responsive nanosystems for target therapy have been a promising approach to control the release and delivery of therapeutic agents at the target sites. In addition, it is equally important to improve the drug therapeutic effect on tumors, and combination 
therapies have been suggested [2,3]. The idea is to achieve an appropriate synergistic effect between two or more treatment methodologies, such as chemotherapy, hyperthermia, and/or radiotherapy, to decrease drug resistance, and improve the therapeutic effect of antitumor compounds by chemosensitization of tumor cells [4].

Multifunctional nanosystems are one of the most promising therapeutic approaches in cancer treatment $[3,5]$. The possibility of combining liposomes with magnetic nanoparticles stands out, allowing theranostic capabilities by simultaneous magnetic guidance to the tumor, combination therapy, and magnetic resonance imaging in a single nanosystem [6-8]. Regarding magnetic nanoparticles, transition metal ferrites, $\mathrm{MFe}_{2} \mathrm{O}_{4}$ (with $\mathrm{M}=\mathrm{Fe}, \mathrm{Ni}, \mathrm{Co}$, $\mathrm{Mn})$, have been the most used. These ferrites are soft-magnetic materials with great superparamagnetic behavior, chemical stability, and mechanical hardness [9-11]. Manganese ferrite nanoparticles are particularly interesting due to the higher magnetic susceptibility compared to the other transition metal ferrites [11,12]. However, toxicity issues have been a concern, and recent investigations recommend the use of nanomaterials with improved biocompatibility [13]. Therefore, organic or inorganic shells have been used to reduce toxicity and control the bioaccumulation, bioelimination, and undesired tissue invasion [14], though it might hinder the preservation of magnetic properties of the core material [15]. The coverage of magnetic nanoparticles with a gold layer offers increased biocompatibility while allowing additional plasmonic features, providing a multifunctional material bearing magnetic and plasmonic capabilities. The easy surface functionalization, low toxicity, and the surface plasmon resonance (SPR) phenomenon have contributed to the use of gold nanoparticles in several biomedical applications [16-18]. In fact, gold-based nanostructures have found extensive use in different technological areas, such as immunologic assays, biosensors, photothermolysis of tumor cells, the detection and control of microbes and drug nanocarriers [19-24]. Gold nanoparticles can be used in photothermal therapy, as they can efficiently convert light into heat. In cancer treatment, this photothermal effect can be used to induce a local temperature increase and, consequently, hyperthermia physiological responses that lead to tumor cell death [22]. Recently, a synergistic cytotoxic effect has been observed by the combination of magnetic hyperthermia with phototherapy [25].

In this work, magnetic nanoparticles of manganese ferrite were decorated with gold nanoparticles or covered by a gold shell. The prepared magnetic/plasmonic nanostructures were entrapped in liposomes and the multifunctional nanosystems were tested as nanocarriers for two new potential antitumor thienopyridine derivatives. Thienopyridine compounds have been described as inhibitors for receptor tyrosine kinase and promising anticancer agents [26-28]. The new compounds, tricyclic lactones (Figure 1), have shown promising antitumor activity [28], exhibiting very low inhibitory concentrations in human colorectal adenocarcinoma (HCT-15 cell line) and non-small cell lung cancer (NCI-H460 cell line) (Table 1). These compounds were incorporated in the magnetic/plasmonic nanosystems and the antiproliferative activity was tested in vitro against the human tumor cell line NCI-H460.

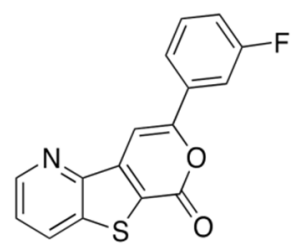

Compound 1

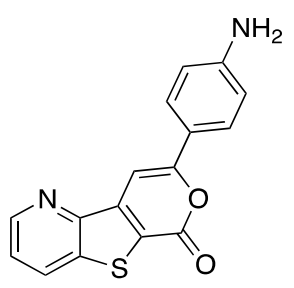

Compound 2

Figure 1. Structure of the tricyclic lactone derivatives of thienopyridine. 
Table 1. Growth inhibitory concentrations $\left(\mathrm{GI}_{50}\right)$ of compounds $\mathbf{1}$ and $\mathbf{2}$ in human tumor cell lines.

\begin{tabular}{ccc}
\hline $\mathbf{G I}_{\mathbf{5 0}}(\boldsymbol{\mu M})[28]$ & Compound 1 & Compound 2 \\
\hline HCT-15 & $7.4 \pm 1.1$ & $12.6 \pm 2.9$ \\
NCI-H460 & $7.3 \pm 0.1$ & $11.4 \pm 0.9$ \\
\hline
\end{tabular}

\section{Materials and Methods}

All solutions were prepared using spectroscopic -grade solvents and ultrapure water of Milli-Q grade (MilliporeSigma, St. Louis, MO, USA).

\subsection{Synthesis of Manganese Ferrite/Gold Nanoparticles}

\subsubsection{Manganese Ferrite Nanoparticles Preparation}

Manganese ferrite nanoparticles (NPs) were produced through the coprecipitation method. Briefly, to a $5 \mathrm{~mL}$ aqueous solution that contained $612 \mu \mathrm{L}$ of $50 \% \mathrm{NaOH}$ (product number 43617 from Sigma-Aldrich, St. Louis, MO, USA) at $90{ }^{\circ} \mathrm{C}, 1 \mathrm{~mL}$ of a mixture of $0.25 \mathrm{M} \mathrm{MnSO}_{4} . \mathrm{H}_{2} \mathrm{O}$ (product number 1.05941 from Sigma-Aldrich, St. Louis, MO, USA) and $0.5 \mathrm{M} \mathrm{FeCl}_{3} \cdot 6 \mathrm{H}_{2} \mathrm{O}$ (product number 236489 from Sigma-Aldrich, St. Louis, MO, USA) was added, drop by drop, under magnetic stirring. After two hours at $90{ }^{\circ} \mathrm{C}$, manganese ferrite nanoparticles $\left(\mathrm{MnFe}_{2} \mathrm{O}_{4}\right)$ were obtained. For purification, the obtained nanoparticles were washed several times by repeated centrifugations and magnetic decantation, followed by drying at $100{ }^{\circ} \mathrm{C}$.

\subsubsection{Gold Nanoparticles Preparation}

A stable solution of gold nanoparticles in toluene was prepared following a method similar to that described by Brust et al. [29]. Briefly, an aqueous solution of gold (III) chloride hydrate (30 mM) (product number 254169, from Sigma-Aldrich, St. Louis, MO, USA) was mixed with tetraoctylammonium bromide (product number 426288 from SigmaAldrich, St. Louis, MO, USA) $(50 \mathrm{mM})$ in toluene. The latter acts as a phase-transfer reagent, allowing the solubilization of gold ions in the toluene organic phase. Then, sodium borohydride (product number 632287 from Sigma-Aldrich, St. Louis, MO, USA) $(0.4 \mathrm{M})$ was slowly added, under magnetic stirring. The obtained gold nanoparticles were washed with deionized water by centrifugation cycles.

\subsubsection{Synthesis of Gold-Seed Manganese Ferrite Nanoparticles}

$1,1^{\prime}$-carbonyldiimidazole (CDI) (product number 705284 from Sigma-Aldrich, St. Louis, $\mathrm{MO}, \mathrm{USA}$ ) was used to promote the covalent coupling of cysteamine to the hydroxyl surface groups of the manganese ferrite nanoparticles. Firstly, $5 \mathrm{~mL}$ of dried dioxane was used as the solvent for the coupling of $1 \mathrm{mg}$ magnetic nanoparticles with a 5-fold molar excess of CDI over metals concentration, under sonication at $60{ }^{\circ} \mathrm{C}$. After purification by centrifugation/sedimentation cycles using ethanol, cysteamine was added at the same 5 -fold molar excess and the system was allowed to react for $1 \mathrm{~h}$ at $60{ }^{\circ} \mathrm{C}$, under sonication. Upon washing with ethanol and drying in an oven, cysteamine-functionalized (product 8.02835 from Sigma-Aldrich, St. Louis, MO, USA) manganese ferrite nanoparticles were dispersed in toluene. Upon the addition of a diluted solution of gold nanoparticles in toluene (3 mL, 1:19.75) a color change occurred, which indicates the gold surface coupling with $\mathrm{SH}$ groups from cysteamine molecules pending on the surface of magnetic nanoparticles. This was further confirmed by solution color disappearance when the resulting nanoparticles were accumulated on the wall of the tube by the use of a small magnet. Finally, the manganese ferrite nanoparticles decorated with gold were washed with ethanol by magnetic decantation.

\subsubsection{Synthesis of Gold-Coated Manganese Ferrite Core-Shell Nanoparticles}

Gold-coated manganese ferrite core-shell nanoparticles were prepared by the growth and coalescence of the gold-decorated nanoparticles as obtained in the previous section. 
The procedure was based on a previously reported "seeding" method [30]. Briefly, to a $1.5 \mathrm{~mL}$ aqueous solution of $\mathrm{MnFe}_{2} \mathrm{O}_{4}$ decorated with gold nanoparticles ([Au] $=0.6 \mathrm{mM}$ ), $2.4 \mathrm{~mL}$ of $\mathrm{HAuCl}_{4}(0.01 \%)$ and $100 \mu \mathrm{L}$ of hydroxylamine (product number 255580 from Sigma-Aldrich, St. Louis, MO, USA) $(40 \mathrm{mM})$ were added. Additional growth was promoted by the further addition of $100 \mu \mathrm{L}$ of $1 \% \mathrm{HAuCl}_{4}$. Purification was conducted by washing with water through magnetic decantation and, at the end, the particles were dispersed in ethanol. In order to monitor the gold shell formation, absorption spectra were measured in $10 \mathrm{~s}$ intervals.

\subsection{Preparation of Magnetoliposome-Type Structures}

For the preparation of magnetoliposome-type structures, the lipid DPPC (dipalmitoylphosphatidylcholine, product 850355P from Sigma-Aldrich, St. Louis, MO, USA) was used, in a final concentration of $2 \mathrm{mM}$. A solution of manganese ferrite/gold nanoparticles, resulting from the process in Section 2.1.3 or Section 2.1.4, in absolute ethanol $(1.5 \mathrm{~mL})$ was prepared. Then, octadecylamine (ODA) (product number 305391, from Sigma-Aldrich, St. Louis, MO, USA), in a 5-fold excess, was added to the nanoparticles, and this solution was stirred for one hour. The solution was washed, and successive centrifugation and magnetic decantation were employed, to remove unbound ODA. After this step, an ethanolic solution of DPPC was added to the solution of nanoparticles covered with ODA. After mixing and solvent evaporation, a lipid film was obtained. Then, ultrapure water was added, and the mixture was ultrasonicated, to promote self-assembling into magnetoliposome formation, followed by two washing steps to remove excess of lipids.

The antitumor tricyclic lactones $\mathbf{1}$ or $\mathbf{2}$ were incorporated into the liposome-type structures (containing the manganese ferrite/gold nanoparticles) by the injection of an ethanolic solution immediately before the formation of the lipid film step.

\subsection{Preparation of Giant Unilamellar Vesicles (GUVs)}

The thin-film hydration method was used to prepare the giant unilamellar vesicles of soybean lecithin (L- $\alpha$-phosphatidylcholine from soybean) (product number 524617 from Sigma-Aldrich, St. Louis, MO, USA). The methodology described by Tamba et al. was employed, consisting of a pre-hydration of the soybean lecithin $(1 \mathrm{mM})$ thin film with $40 \mu \mathrm{L}$ of water and incubation at $45^{\circ} \mathrm{C}$ for $30 \mathrm{~min}$, followed by the addition of $3 \mathrm{~mL}$ of a glucose (product number G8270 from Sigma Aldrich, St. Louis, MO, USA) aqueous solution (0.1 M) and incubation at $37^{\circ} \mathrm{C}$ for $2 \mathrm{~h}[31,32]$. In order to remove multilamellar vesicles and lipid aggregates, the suspension was centrifuged for $30 \mathrm{~min}$ under $14,000 \times \mathrm{g}$.

\subsection{Spectroscopic Measurements}

\subsubsection{Absorption and Fluorescence Spectra}

The absorption and emission spectra were obtained using the spectrophotometer Shimadzu UV-3600 Plus UV-vis-NIR (Shimadzu Corporation, Kyoto, Japan) and the spectrofluorimeter Horiba Fluorolog 3 (HORIBA Jobin Yvon IBH Ltd., Glasgow, UK), respectively. The latter included a temperature-controlled sample cuvette holder, double monochromators in excitation and emission, and Glan-Thompson polarizers (for fluorescence anisotropy measurements).

The steady-state fluorescence anisotropy, $r$, is calculated by the equation below.

$$
r=\frac{I_{\mathrm{VV}}-G I_{\mathrm{VH}}}{I_{\mathrm{VV}}+2 G I_{\mathrm{VH}}}
$$

In Equation (1), $I_{\mathrm{VV}}$ and $I_{\mathrm{VH}}$ represent the fluorescence intensities obtained with vertical or horizontal polarization using vertically polarized excitation light, respectively. The instrument correction factor $(G)$ is obtained by the ratio $I_{\mathrm{HV}} / I_{\mathrm{HH}}$, where $I_{\mathrm{HV}}$ and $I_{\mathrm{HH}}$ are the corresponding emission intensities using horizontally polarized excitation light. 


\subsubsection{Drug Encapsulation Efficiency}

Encapsulation studies of the potential antitumor drugs in the nanocarriers were performed using Amicon ${ }^{\circledR}$ Ultra centrifugal filter units $100 \mathrm{kDa}$ (Merck Millipore, Darmstadt, Germany) using 60 min centrifugation at 11,000 rpm. Upon solvent evaporation and redispersion in ethanol, the amount of non-encapsulated dye was determined through fluorescence emission using a calibration curve. The encapsulation efficiency $(E E \%)$ is then obtained by:

$$
E E(\%)=\frac{(\text { total amount }- \text { amount of non encapsulated compound })}{\text { total amount }} \times 100
$$

The $E E(\%)$ standard deviation (SD) was calculated using three independent measurements.

\subsection{Characterization of Structural and Magnetic Properties}

Electron microscopy images of the synthesized nanoparticles and nanosystems were obtained in a JEM 2010F high-resolution transmission electron microscope (HR-TEM) from JEOL Ltd. operating at $200 \mathrm{kV}$, at C.A.C.T.I (Centro de Apoio Científico e Tecnolóxico á Investigación), Vigo, Spain. STEM images were recorded using a NanoSEM-FEI Nova 200 (FEI Company, Hillsboro, OR, USA), operating at $15 \mathrm{kV}$, coupled to an Electron Dispersive Spectroscopic analyzer (EDS) and Electron Backscatter Diffraction EDAX-Pegasus X4M analyzer (AMETEK Inc., Berwyn, PA, USA) and detection system (EBSD) at SEMAT (Serviços de Caracterização de Materiais, Guimarães, Portugal). The samples were prepared by placing a drop of a solution-dispersed material onto a copper grid with Formvar/carbon (Agar Scientific Ltd., Essex, UK) and drying. The ImageJ software (National Institutes of Health (NIH), version 1.53c, Bethesda, MD, USA), was used for the manual selection of ellipsoidal contours from which particle diameters were calculated using the particles area. The corresponding histograms were fitted to Gaussian distributions. Dynamic light scattering (DLS) measurements at $25^{\circ} \mathrm{C}$ and a $173^{\circ}$ detector angle were obtained using NANO ZS Malvern Zetasizer (Malvern Panalytical Ltd., Malvern, UK) equipped with a He-Ne laser $(\lambda=632.8 \mathrm{~nm})$. These measurements allowed the estimation of the magnetoliposomes-type nanosystem's mean diameter and size distribution. For each sample, five independent measurements were performed. The crystallography measurements were performed in an X-ray diffraction (XRD) diffractometer equipment PAN'alytical X'Pert PRO diffractometer (Malvern Panalytical Ltd., Malvern, UK), operating in a Bragg-Brentano configuration using $\mathrm{CuK}_{\alpha}$ radiation. Magnetic properties were investigated using a superconducting quantum interference device (SQUID) magnetometer Quantum Design MPMS5XL (Quantum Design Inc., San Diego, CA, USA), operating with an up to $5.5 \mathrm{~T}$ applied magnetic field.

\subsection{Measurement of the Photothermal Effect}

The irradiation source consisted of a Xenon arc lamp $(200 \mathrm{~W})$ focused through a Thorlabs FEL0600 (Thorlabs Inc., Newton, NJ, USA) long-pass filter with a cut-on wavelength at $600 \mathrm{~nm}$, on a cell holder with fiber adaptors. In this way, only gold nanoparticles absorb the irradiation light, with minimal excitation of the dye Nile Red. Magnetoliposomes incorporating Nile Red were divided in two aliquots. For one of these aliquots, absorption spectra were measured at several temperatures by the use of a water bath. For the other, absorption spectra were measured after several irradiation times. The experimental setup is represented in Scheme 1. The monitoring channel used a $75 \mathrm{~W}$ halogen bulb and a compact CCD optical fiber spectrophotometer $(350-700 \mathrm{~nm}, \Delta \lambda<0.5 \mathrm{~nm}$, slit $=20 \mu \mathrm{m}$, CCS100 Thorlabs Inc., Newton, NJ, USA) with 20 ms acquisition time and 100 averages. In order to avoid the impact of scattered light from the irradiation lamp, the irradiation optical channel was blocked during the acquisition of the monitoring light intensity. An aqueous dispersion with $\mathrm{P} 25 \mathrm{TiO}_{2}$ nanoparticles, with approximately the same scattering effect as the magnetoliposomes solution, was used as a reference. 


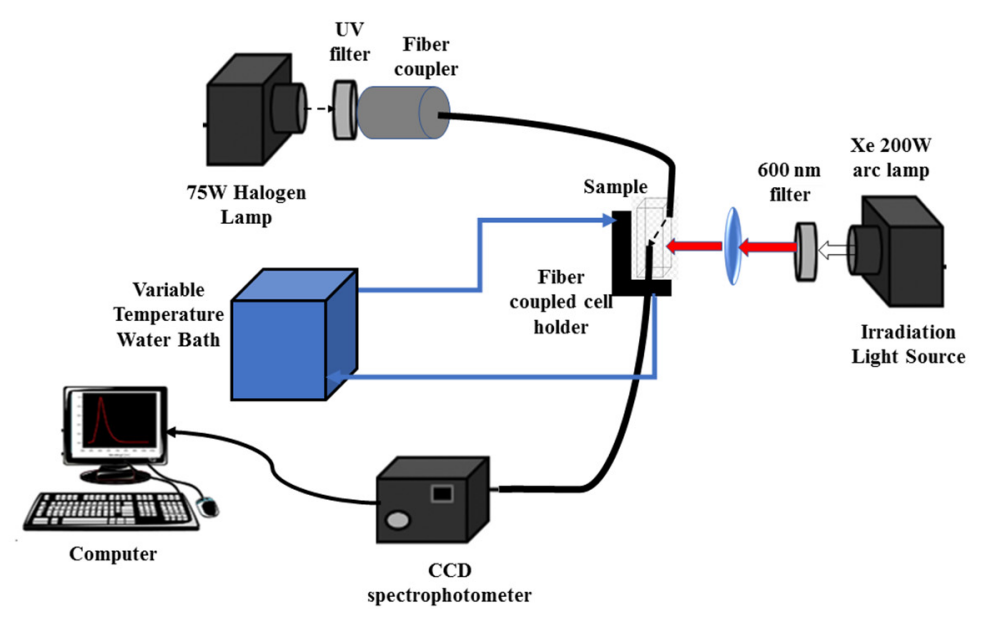

Scheme 1. Representation of the photothermal effect measurement setup.

\subsection{Studies in Cell Lines}

The in vitro cytotoxicity of the magnetoliposomes loaded with compounds $\mathbf{1}$ and 2, with different concentrations $(2.28 \mu \mathrm{M}$ to $146 \mu \mathrm{M}$, for compound 1 and $3.50 \mu \mathrm{M}$ to $228 \mu \mathrm{M}$, for compound 2), was evaluated in the primary non-tumor cell line PLP2 and a non-small cell lung cancer line (NCI-H460). Cells were obtained from the European Collection of Cell Cultures (Salisbury, UK). The in vitro effect on the growth of cell lines was evaluated according to the procedure adopted by the National Cancer Institute (NCI) (Bethesda, MD, USA) in the "In vitro Anticancer Drug Discovery Screen" using the protein-binding dye sulforhodamine B (SRB) to assess cell growth [33,34].

The cells were maintained in a humidified air incubator containing $5 \% \mathrm{CO}_{2}$, at $37{ }^{\circ} \mathrm{C}$, as adherent cell cultures in the RPMI-1640 medium containing 10\% heat-inactivated FBS. Every cell line was plated to a density of $1.0 \times 10^{4}$ cells per well in 96-well plates and allowed to attach for $24 \mathrm{~h}$. After that, the cells were treated for $48 \mathrm{~h}$ with different solutions. After this incubation period, the adherent cells were fixed by adding cold 10\% trichloroacetic acid (TCA) $(100 \mu \mathrm{L})$ and incubated for $60 \mathrm{~min}$ at $4{ }^{\circ} \mathrm{C}$. Finally, the plates were washed with deionized water and dried. Then, an SRB assay was used. A $100 \mathrm{~mL}$ SRB solution $(0.1 \%$ in $1 \%$ acetic acid) was placed in each plate-well and incubated at room temperature for half an hour. The plates were washed with $1 \%$ acetic acid solution to remove unbound SRB. After drying, $200 \mu \mathrm{L}$ of a $10 \mathrm{mM}$ Tris-HCl buffer was added to the SRB bound in the plates and the absorbance was measured in a microplate reader at $540 \mathrm{~nm}$ to estimate the $\mathrm{GI}_{50}$ values (concentration that inhibited $50 \%$ of net cell growth).

For the cytotoxicity assays of the drug-loaded magnetoliposomes under irradiation, a halogen/tungsten lamp (24 V and $250 \mathrm{~W}$, OSRAM, Porto, Portugal) with a fluence rate of $19-20 \mu \mathrm{W} / \mathrm{cm}^{2}$ (measured with an ILT 1400-A radiometer equipped with one SEL033 detector (ILT, Peabody, MA, USA) was used (Figure 2). Cells were continuously irradiated for $30 \mathrm{~min}$ followed by $24 \mathrm{~h}$ after incubation. A $1 \mathrm{M}$ aqueous iron(III) nitrate solution was placed between the lamp and the cells as a liquid cut filter to remove the light of wavelengths less than $\sim 500 \mathrm{~nm}$ [35]. The temperature the cells were exposed to was carefully monitored to ensure cell viability. 


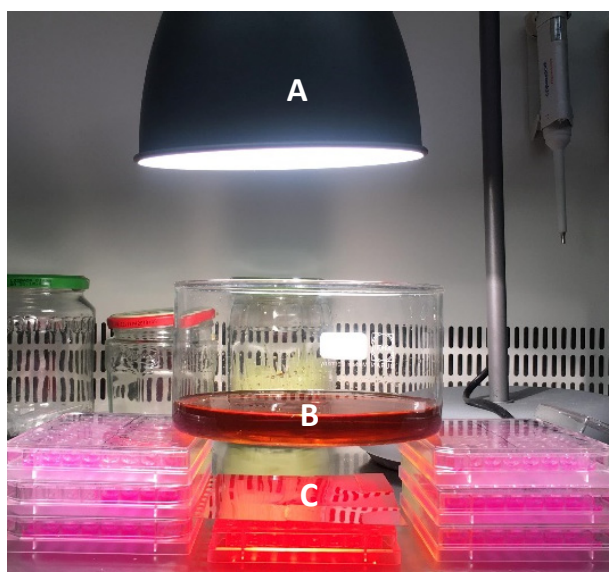

Figure 2. In vitro assays using cell lines under irradiation. (A) Halogen/tungsten lamp; (B) aqueous solution of iron(III) nitrate, (C) 96-well plates and cut-off filter to remove light of wavelength below $\sim 500 \mathrm{~nm}$.

\section{Results and Discussion}

\subsection{Photophysical Properties of the Antitumor Compounds}

The antitumor tricyclic lactones $\mathbf{1}$ and $\mathbf{2}$ are fluorescent compounds and this property can be used to monitor the compound location and behavior in the prepared nanosystems. First, UV-Vis absorption and fluorescence measurements were performed in several solvents of different polarity, to assess their potentialities to be used as intrinsic fluorescent probes when loaded in the developed nanosystems. The absorption and normalized fluorescence spectra are displayed in Figure 3 (for compound 1) and Figure 4 (for compound 2). The maximum absorption and emission wavelengths and molar absorption coefficients are shown in Table 2.

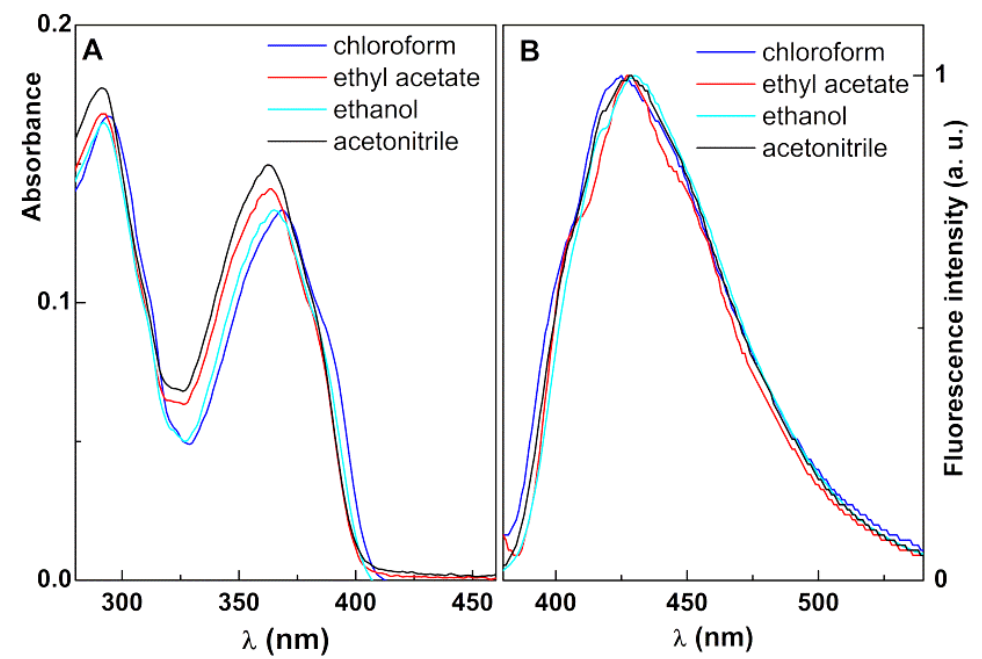

Figure 3. (A) Absorption spectra of $1 \times 10^{-5} \mathrm{M}$ solutions of compound 1 in ethyl acetate, acetonitrile, chloroform, and ethanol. (B) Normalized fluorescence spectra $\left(\lambda_{\mathrm{exc}}=370 \mathrm{~nm}\right)$ of $1 \times 10^{-6} \mathrm{M}$ solutions of compound 1 in the same solvents. 


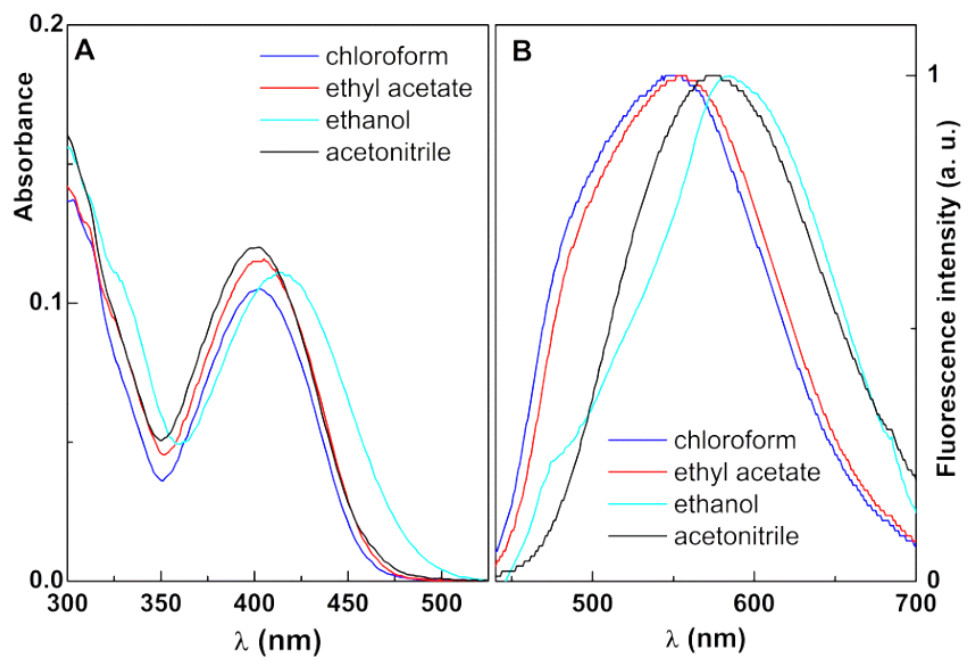

Figure 4. (A) Absorption spectra of $1 \times 10^{-5} \mathrm{M}$ solutions of compound 2 in ethyl acetate, acetonitrile, chloroform, and ethanol. (B) Normalized fluorescence spectra $\left(\lambda_{\mathrm{exc}}=420 \mathrm{~nm}\right)$ of $1 \times 10^{-6} \mathrm{M}$ solutions of compound 2 in the same solvents.

Table 2. Maximum absorption $\left(\lambda_{\mathrm{abs}}\right)$ and emission $\left(\lambda_{\mathrm{em}}\right)$ wavelengths and molar absorption coefficients $(\varepsilon)$ for compounds $\mathbf{1}$ and $\mathbf{2}$ in several solvents.

\begin{tabular}{ccccc}
\hline \multirow{2}{*}{ Solvent } & \multicolumn{2}{c}{$\boldsymbol{\lambda}_{\mathbf{a b s}} / \mathbf{n m}\left(\varepsilon / \mathbf{1 0}^{\mathbf{4}} \mathbf{M}^{-\mathbf{1}} \mathbf{c m}^{-\mathbf{1}}\right)$} & \multicolumn{2}{c}{$\lambda_{\mathbf{e m}} / \mathbf{n m}$} \\
\cline { 2 - 5 } & Compound 1 & Compound 2 & Compound 1 & Compound 2 \\
\hline Chloroform & $369(1.33)$ & $403(1.05)$ & 425 & 523 \\
Ethyl acetate & $364(1.41)$ & $405(1.16)$ & 427 & 532 \\
Ethanol & $365(1.33)$ & $415(1.10)$ & 430 & 581 \\
Acetonitrile & $363(1.50)$ & $403(1.21)$ & 428 & 568 \\
\hline
\end{tabular}

Both compounds exhibit fluorescence emissions in several solvents, but not in water, which is a common behavior in other thienopyridine derivatives previously studied [36-38]. Compound 2 exhibits a notable influence of solvent in the fluorescence emission, together with significant red shifts relative to compound $\mathbf{1}$, which is a result of the influence of the electron-donating $\mathrm{NH}_{2}$ group. Both antitumor drugs present photophysical stability, as the absorption and emission of the two compounds are stable for several months (Figures S1 and S2 in Supplementary Materials).

\subsection{Nanoparticles Synthesis and Characterization}

\subsubsection{Synthesis of Manganese Ferrite/Gold Nanoparticles}

Good-quality manganese ferrite nanoparticles were produced by co-precipitation, as already reported [39]. The gold nanoparticles were prepared in an organic phase using the Brust-Schiffrin method [29] and tetraoctylammonium bromide (TOAB) as $\mathrm{Au}(\mathrm{III})$ phase-transfer agent. Upon borohydride reduction, TOAB provides stabilization of the formed gold nanoparticles by capping them with octyl chains through the binding of $\left(\mathrm{CH}_{3}\left(\mathrm{CH}_{2}\right)_{7}\right)_{4} \mathrm{~N}^{+} \mathrm{Br}^{-}$ion pairs to the gold surface [40].

The decoration of manganese ferrite nanoparticles with gold was idealized through the use of cysteamine molecules $\left(\mathrm{NH}_{2} \mathrm{CH}_{2} \mathrm{CH}_{2} \mathrm{SH}\right)$ as bridges. $\mathrm{CDI}$ was chosen to enable the coupling of $\mathrm{NH}_{2}$ groups of cysteamine with hydroxyl $(-\mathrm{OH})$ surface groups of manganese ferrite, with the remaining thiol $(-\mathrm{SH})$ providing strong chemisorption sites for gold nanoparticles, thus resulting in gold-decorated magnetic manganese ferrite nanoparticles.

Additional $\mathrm{Au}$ deposition on the decorating gold nanoparticles occurred via the "seeding" method using hydroxylamine as the reductant of $\mathrm{Au}^{3+}$ ions (Figure 5). The idea of that method consists of an enhanced $\mathrm{Au}^{3+}$ reduction reaction rate on the surface 
of pre-existent gold nanoparticles (seeds), so that the nucleation of new particles in the solution cannot compete with the growth of the seeds through the gold deposition process [30]. The coalescence of growing gold nanoparticles will eventually result in gold shell formation. Figure $5 \mathrm{~B}$ evidences the growth of the gold shell with time and the addition of hydroxylamine.
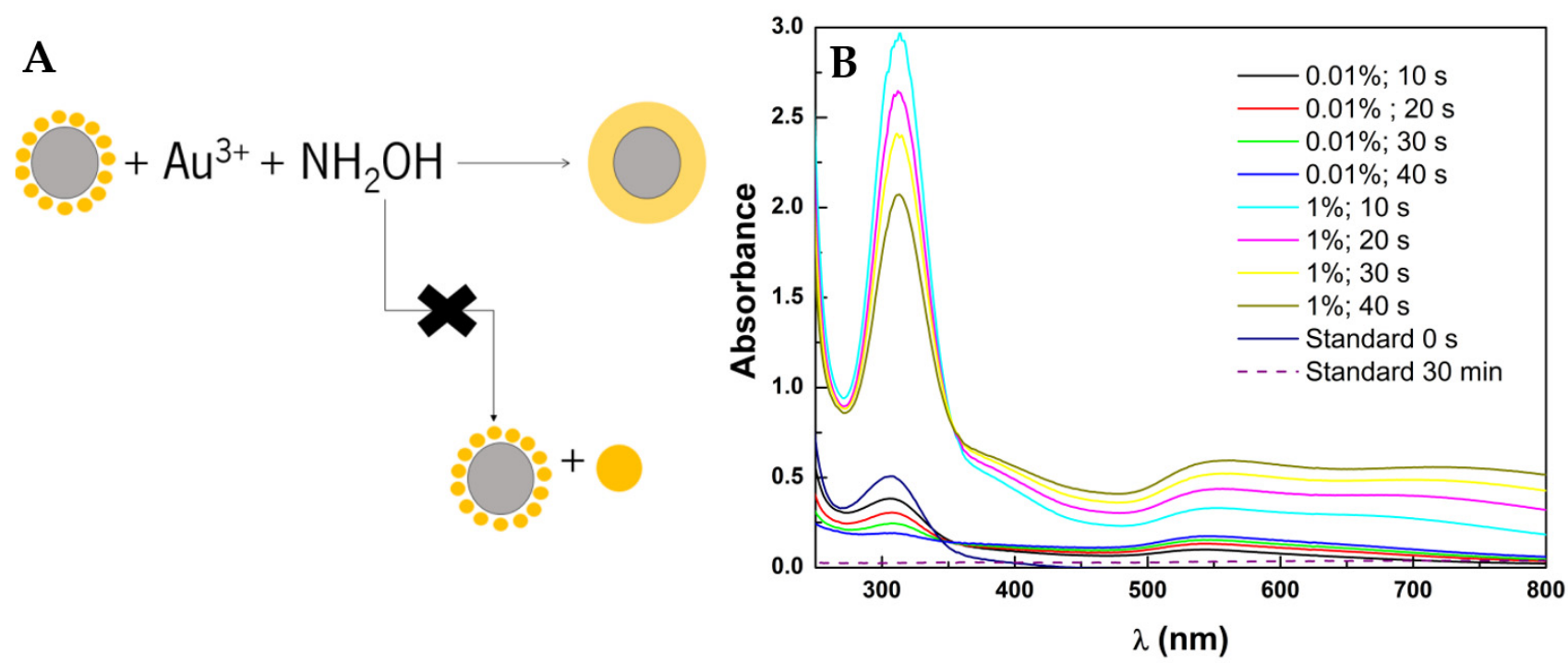

Figure 5. (A) Representation of the seeding method using hydroxylamine for the growth of a gold shell. (B) Absorption spectra of manganese ferrite/gold core/shell nanoparticles with increasing time, after the addition of hydroxylamine and chloroauric acid $(0.01 \%$ and $1 \%)$.

The potential of manganese ferrite/gold core/shell nanoparticles (with a $5.85 \mathrm{~nm}$ gold shell) covered by lipid bilayers for phototherapy applications in cancer treatment was previously anticipated [41]. However, the magnetic properties of the nanoparticles were very poor, hindering the simultaneous application of magnetic hyperthermia, together with a limited photothermia effect [41]. More recently, nickel ferrite nanoparticles decorated with gold nanoparticles or with a gold shell, prepared by the same methodology used in this work, were revealed to be more promising for applications in thermotherapy [42]. However, toxicity issues arise when using nickel ferrite nanoparticles, also considering their easy degradation. So, manganese ferrite nanoparticles are preferred and have revealed no toxicity in primary cells when entrapped in liposomes [38]. Here, using the seeding method, manganese ferrite nanoparticles covered with a shell of gold and decorated with gold were prepared and covered with a liposome-like structure. The absorption spectra are shown in Figure 6. The absorption spectrum of manganese ferrite/gold core/shell nanoparticles exhibits a broader and red-shifted plasmon band relative to the decorated nanoparticles, with the plasmon band extending to $800 \mathrm{~nm}$, allowing NIR irradiation.

The position of the plasmon absorption band of gold nanoshells varies with the shell thickness and the refraction index of both core and surrounding media [43]. Previous similar preparations of $\mathrm{MnFe}_{2} \mathrm{O}_{4}$ nanoparticles resulted in an average size of $\sim 25 \mathrm{~nm}$ [39]. From published theoretical studies [44], it is possible to conclude that the gold resonance peak is predicted to occur at $595.6 \mathrm{~nm}$ for a gold shell of $5 \mathrm{~nm}$ over an air core of $25 \mathrm{~nm}$ in a water medium, while if the gold shell is $10 \mathrm{~nm}$, it is expected to occur at $552.2 \mathrm{~nm}$. The increase in the core refraction index results in a red shift of the plasmon resonance peak [43]. Thus, the absorption spectrum indicates a shell between 5 and $10 \mathrm{~nm}$, while for the gold-decorated NPs, the spectrum is typical of clusters of gold spheres [45]. 


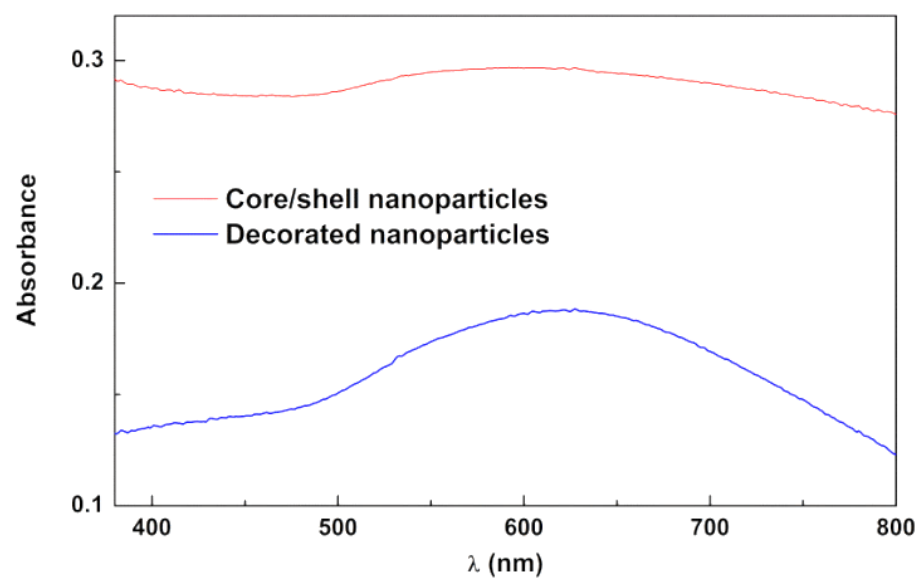

Figure 6. UV-Visible absorption spectra of aqueous dispersions of $\mathrm{MnFe}_{2} \mathrm{O}_{4}$ nanoparticles decorated with gold and $\mathrm{MnFe}_{2} \mathrm{O}_{4} / \mathrm{Au}$ core/shell nanoparticles.

\subsubsection{XRD Analysis}

XRD results of the prepared manganese ferrite conjugated with gold (Figure 7) confirm the crystallinity of the prepared nanoparticles. A Rietveld analysis was performed using BGMN [46], as implemented in Profex software [47]. The required structure files were obtained through the import process of CIF file nr. 9013035 for gold (space group Fm-3m) and CIF file nr. 2300618 for $\mathrm{MnFe}_{2} \mathrm{O}_{4}$ (space group Fd-3m). Diffraction peaks of gold are observed at $2 \theta=38.2^{\circ}\left(\begin{array}{lll}1 & 1 & 1\end{array}\right), 44.4^{\circ}(200), 64.6^{\circ}$ (2 20 ) $), 77.6^{\circ}$ (3 111$), 81.7^{\circ}$ (2 2 2), and $98.2^{\circ}(400)$ and are marked with a filled red square in Figure 7 , while for $\mathrm{MnFe}_{2} \mathrm{O}_{4}$, they occur at $2 \theta=18.1^{\circ}(111), 29.7^{\circ}(220), 35.0^{\circ}$ (3 11 1), 36. $6^{\circ}$ (2 22$), 42.5^{\circ}$ (4 00$), 46.6^{\circ}$ (3 31 ),

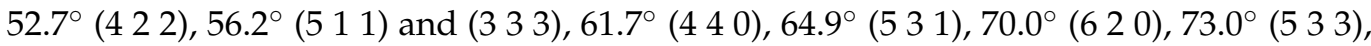

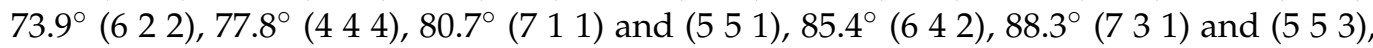
and $93.0^{\circ}(800)$. All diffraction peaks are identified, so there are no other crystallographic phases present in the sample. Good fits were obtained, and the main results obtained by the Rietveld analysis are shown in Table 3.

Table 3. Calculated $\mathrm{R}_{\mathrm{P}}$ and $\chi^{2}$ parameters, phase sizes, and percentages obtained by Rietveld refinement of X-ray diffraction patterns of $\mathrm{Au} @ \mathrm{MnFe}_{2} \mathrm{O}_{4}$ (gold-decorated nanoparticles) and $\mathrm{MnFe}_{2} \mathrm{O}_{4} / \mathrm{Au}$ (core/shell nanoparticles).

\begin{tabular}{|c|c|c|c|c|c|c|c|}
\hline \multirow[t]{2}{*}{ Sample } & \multirow[t]{2}{*}{$\left.\mathrm{O}_{x, y, z}{ }^{*}\right)$} & \multirow[t]{2}{*}{$i(* *)$} & \multicolumn{2}{|c|}{$\begin{array}{c}\text { Phase Size (nm) } \\
\text { Lattice Constant (nm) }\end{array}$} & \multirow[t]{2}{*}{$\mathrm{Au}(w t \%)$} & \multirow[t]{2}{*}{$\mathbf{R}_{\mathbf{P}}$} & \multirow[t]{2}{*}{$x^{2}$} \\
\hline & & & $\mathrm{MnFe}_{2} \mathrm{O}_{4}$ & $\mathrm{Au}$ & & & \\
\hline $\mathrm{Au} @ \mathrm{MnFe}_{2} \mathrm{O}_{4}$ & 0.3865 & $0.2\left(^{+}\right)$ & $\begin{array}{c}26.7 \\
0.8498\end{array}$ & $\begin{array}{c}41.9 \\
0.4078\end{array}$ & 12.8 & 10.5 & 1.96 \\
\hline $\mathrm{MnFe}_{2} \mathrm{O}_{4} / \mathrm{Au}$ & 0.3885 & $0.2\left(^{+}\right)$ & $\begin{array}{c}28.8 \\
0.8497\end{array}$ & $\begin{array}{c}27.9 \\
0.4078(+)\end{array}$ & 74.7 & 9.4 & 1.62 \\
\hline
\end{tabular}

$\left(^{*}\right)$ Value of $\mathrm{O}_{x, y, z}$ in CIF file 2300618 is $0.25053\left(^{(* *}\right)$ Degree of inversion $\left(^{+}\right)$fixed to value in reference [48].

A huge increase in the gold phase diffraction peaks' intensity occurs as a result of the seeding process (Figure 7). This confirms the predictable increase in gold content that would result from the growth of the spherical gold NPs decorating the $\mathrm{MnFe}_{2} \mathrm{O}_{4}$ surface expectedly into a gold shell. 


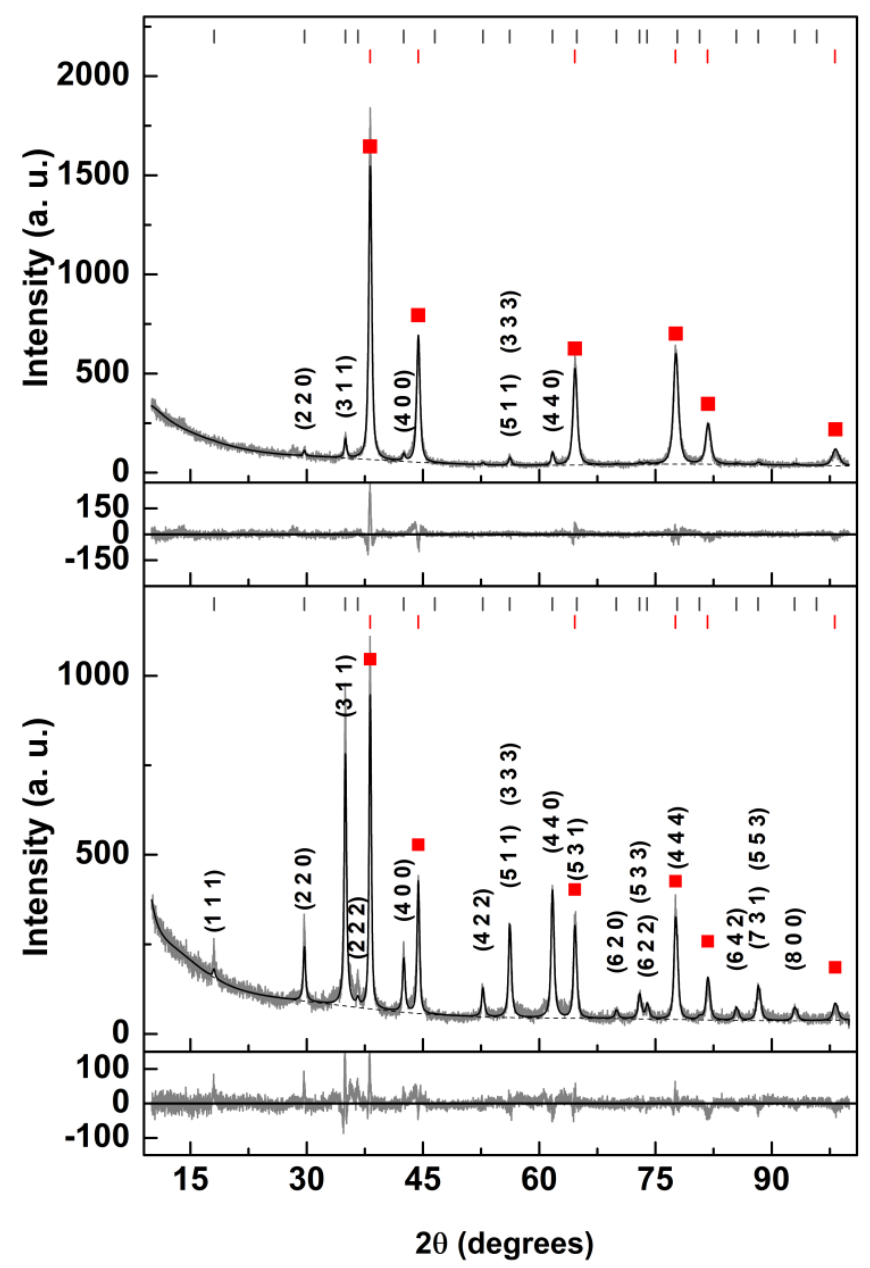

Figure 7. X-ray diffraction pattern of manganese ferrite/gold core/shell nanoparticles (above) and manganese ferrite decorated with gold nanoparticles (below). Gray lines: Experimental patterns; black lines: Fitted patterns; short-dashed lines: background. Miller indices of manganese ferrite are indicated in black; the gold peaks are marked as red squares.

Considering that, for core-shell nanoparticles, a given $\mathrm{X}$-ray interacts with the gold phase two times, $96 \%$ gold content would be expected ( $56.7 \mathrm{~nm}$ overall size; $27.9 / 2=14 \mathrm{~nm}$ shell thickness). A shell thickness of $5 \mathrm{~nm}$ ( $38.8 \mathrm{~nm}$ overall size) is more compatible with the observed absorption spectra and corresponds to a weight percentage of $84.7 \%$. This allows us to estimate a coating efficiency of $86 \%$. The size obtained from the broadening of gold diffraction peaks has been found to be unreliable [41,49].

For the gold-decorated NPs, the $41.9 \mathrm{~nm}$ size, obtained for the gold phase from the Rietveld analysis, is not compatible with the 5-7 nm value reported for gold spherical nanoparticles synthesized with a similar method to the one used in this work [50]. Even if the size of gold-decorated NPs is $41.9 / 2 \mathrm{~nm}$, the average number of spherical gold NPs per decorated $\mathrm{MnFe}_{2} \mathrm{O}_{4}$ nanoparticle is estimated to be 0.078 , from the determined gold weight percentage of $12.8 \%$. Considering the 5 to $7 \mathrm{~nm}$ reported size range, that average number is estimated to be, respectively, from 5.8 to 2.1. This range is much more reasonable, indicating that the size of the gold phase determined from XRD analysis is affected by unknown effects and/or experimental artifacts.

\subsubsection{Transmission Electron Microscopy (TEM)}

TEM images of manganese ferrite nanoparticles shelled with gold or decorated with gold nanoparticles are shown, respectively, in Figure S3A,C in Supplementary Materials. The decorated nanoparticles image shows distinct features (Figure S3E in Supplementary 
Materials), that consist of small particles arranged in a pattern, in areas with underlying intensity clearly different from the image background. These can be interpreted as ferrite nanoparticles with small gold nanoparticles above their surface. The histograms in Figure S3B,D,F (see Supplementary Materials) were obtained by manually outlining the particles in, respectively, Figure S3A,C,E, using the elliptical selection tool of ImageJ and considering its size as the diameter of a circle with an equivalent area. Gaussian distribution fits to the histograms allowed size estimations of $30 \pm 4 \mathrm{~nm}$ for the core/shell nanoparticles, $46 \pm 9 \mathrm{~nm}$ in the case of the decorated nanoparticles, and $10 \pm 2 \mathrm{~nm}$ for the small particles observed in Figure S3E. These size estimations are compatible with the discussion of the XRD results. Further evidence is shown in Figure S4 in Supplementary Materials, using an SEM microscope. STEM images of core/shell nanoparticles (in Lacey carbon film-coated EM grids) show isolated particles with sizes within the histogram in Figure S3B. The EDS spectrum in Figure S4C confirms the presence of gold and atomic percentages that are compatible with the existence of $\mathrm{MnFe}_{2} \mathrm{O}_{4}$. The topography of the NPs' surface exhibited in Figure S4D, through the detection of secondary electrons (SE) by the TLD detector, shows either particles covered by a very bright homogeneous layer (marked with a thin arrow) or particles with bright spots (marked with a thick arrow). The latter could be NPs decorated with gold that, through the seed-mediated growth process, have not fully evolved to a continuous gold layer that corresponds to the former.

\subsubsection{Magnetic Properties}

Manganese ferrite nanoparticles are soft magnetic materials with interesting magnetic properties for biomedical applications, yet such properties strongly depend on the surface, due to increased effects arising from the size decrease. Surface functionalization with gold can lead to increased surface effects of the magnetic core. The surface magnetic moments of the core can be disordered by the interaction with gold electrons leading to a larger spin canting resulting in an overall decrease in magnetic properties. Gold has a density four times larger than manganese ferrite and is diamagnetic in the bulk state. However, a ferromagnetic behavior is expected for very small-sized nanoparticles $(4-5 \mathrm{~nm})$ [51]. Therefore, in this work, the magnetic contribution of the overall structure of the magnetic/plasmonic nanoparticles strongly depends on the gold shell or NP size on the surface of the magnetic core. The magnetic properties of the synthetized magnetic/plasmonic nanoparticles were characterized by measuring the magnetic hysteresis loop (Figure 8), which represents the magnetization $(\mathrm{M})$ as a function of the applied magnetic field $(\mathrm{H})$ ). Typically, manganese ferrite nanoparticles have a partially inverse spinel structure, with about $80 \%$ of $\mathrm{Mn}^{2+}$ ions located at tetrahedral sites and only $20 \%$ at octahedral sites [48]. Knowing that $\mathrm{Mn}^{2+}$ and $\mathrm{Fe}^{3+}$ ions contribute to large magnetic moments $\left(5 \mu_{\mathrm{B}}\right)$ and that the structural formula for ion distribution is represented by $\left(\mathrm{Mn}_{1-\delta} \mathrm{Fe}_{\delta} \uparrow\right)\left[\mathrm{Fe}_{2-\delta} \mathrm{Mn}_{\delta} \downarrow\right] \mathrm{O}_{4}$, the expected net magnetic moment of manganese ferrite NPs is $2.0 \mu_{\mathrm{B}}$ per $\mathrm{MnFe}_{2} \mathrm{O}_{4}$ (for $\delta=0.20$ ) [52].

Figure 8 displays the hysteresis loops of the magnetic/plasmonic samples measured at $300 \mathrm{~K}$ and $5 \mathrm{~K}$, the low field region being shown at insets. The saturation magnetization of magnetic/plasmonic NPs at $300 \mathrm{~K}$ exhibits lower values than those measured at $5 \mathrm{~K}$, due to the thermal fluctuations of nanoparticle magnetic moments at higher temperatures. At $5 \mathrm{~K}$, both samples show larger hysteresis with higher values of remnant magnetization and the coercive field, presenting ferromagnetic behavior with a corresponding magnetic squareness ratio above 0.1 (Table 4 ). 

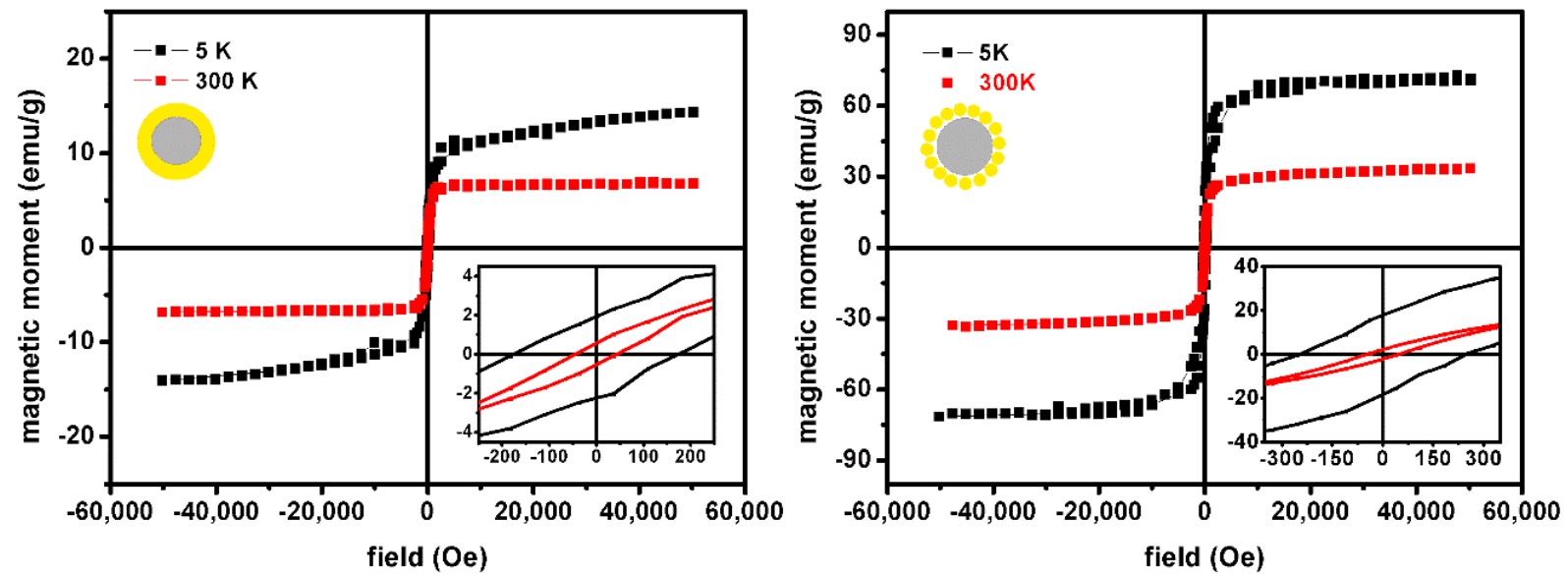

Figure 8. Magnetization hysteresis loops of $\mathrm{MnFe}_{2} \mathrm{O}_{4} / \mathrm{Au}$ core/shell nanoparticles (left) and $\mathrm{MnFe}_{2} \mathrm{O}_{4} \mathrm{NPs}_{\text {decorated with }}$ $\mathrm{Au}$ (right) at $5 \mathrm{~K}$ and $300 \mathrm{~K}$. Insets: Enlargement of the loops in the low field region.

Table 4. Coercive field $\left(H_{\mathrm{c}}\right)$, remnant magnetization $\left(M_{\mathrm{r}}\right)$, saturation magnetization $\left(M_{\mathrm{s}}\right)$, and magnetic squareness ratio $\left(M_{\mathrm{r}} / \mathrm{M}_{\mathrm{S}}\right)$ of $\mathrm{MnFe}_{2} \mathrm{O}_{4} / \mathrm{Au}$ core/shell nanoparticles and $\mathrm{MnFe}_{2} \mathrm{O}_{4} \mathrm{NPs}$ decorated with $\mathrm{Au}$, at $5 \mathrm{~K}$ and $300 \mathrm{~K}$. The magnetic properties of $\mathrm{MnFe}_{2} \mathrm{O}_{4}$ nanoparticles are also shown for comparison [39].

\begin{tabular}{ccccccc}
\hline & $\mathbf{T}(\mathbf{K})$ & $\boldsymbol{H}_{\mathbf{c}}(\mathbf{O e})$ & $\boldsymbol{M}_{\mathbf{r}}(\mathbf{e m u} / \mathbf{g})$ & $\boldsymbol{M}_{\mathbf{s}}(\mathbf{e m u} / \mathbf{g})$ & $\boldsymbol{M}_{\mathbf{r}} / \boldsymbol{M}_{\mathbf{s}}$ \\
\hline $\mathrm{MnFe}_{2} \mathrm{O}_{4}[39]$ & 300 & 6.30 & 0.58 & 36.00 & 0.02 \\
\cline { 2 - 7 } & 5 & 247.47 & 17.68 & 71.02 & 0.25 \\
$\mathrm{MnFe}_{2} \mathrm{O}_{4} \mathrm{NPs}$ & 300 & 46.23 & 2.17 & 33.66 & 0.06 \\
$\mathrm{MnFe}_{2} \mathrm{O}_{4} / \mathrm{Au}$ core/shell NPs & 5 & 173.82 & 1.93 & 14.43 & 0.13 \\
& 300 & 45.95 & 0.55 & 6.89 & 0.08 \\
\hline
\end{tabular}

At room temperature, synthetized nanoparticles have shown higher hysteresis compared to $\mathrm{MnFe}_{2} \mathrm{O}_{4}$ NPs obtained in previous research [39], yet the magnetic/plasmonic structures have shown superparamagnetic behavior. Both structures (decorated or core/shell) have shown a magnetic squareness ratio below 0.1 (Table 4 ), indicating that more than $90 \%$ of the induced magnetization was lost upon the removal of the external magnetic field [52], hence being promising for biomedical applications. Comparing the saturation magnetization value, at room temperature, of the $\mathrm{MnFe}_{2} \mathrm{O}_{4} \mathrm{NPs}$ previously obtained [39] with the magnetic/plasmonic ones, it is possible to observe a slight decrease for the decorated structure, contrasting with a strong decrease for that of the core/shell (Table 4) as was predicted considering the diamagnetic nature of the gold shell. The small decrease in saturation magnetization for the nanoparticles decorated with gold can be justified by small and/or incomplete coverage of the magnetic core with gold, as observed for nickel ferrite [42]. In addition, this higher value of magnetization of gold-seeded manganese ferrite nanoparticles may also result from an aggregation process that occurs during the seeding process. For the core/shell nanoparticles, a higher $M_{\mathrm{S}}$ value was obtained than for similar nanoparticles prepared by another method [41].

Considering a well-ordered core of $\mathrm{MnFe}_{2} \mathrm{O}_{4}$ covered by a non-magnetic gold shell ("dead layer"), it was possible to estimate the thickness of the gold shell using the magnetic hysteresis cycle, by taking the relation between the saturation magnetization, $M_{s}$, to the particle diameter $(D)$ and the saturation magnetization of the core $\left(M_{s 0}\right)$. The thickness $\delta$ can be calculated through Equation (3) [52],

$$
M_{s}=M_{s 0}\left(1-\frac{6 \delta}{D}\right)
$$


The saturation magnetization depends on the particle size. Chen et al. [53] reported a saturation magnetization of $58 \mathrm{emu} / \mathrm{g}$ for $\mathrm{MnFe}_{2} \mathrm{O}_{4}$ nanoparticles of $13.3 \mathrm{~nm}$ prepared by co-precipitation. With this value, a gold shell with a thickness of $4.23 \mathrm{~nm}$ was estimated for particles with a diameter of $28.8 \mathrm{~nm}$ (from XRD) and $M_{S}=6.89 \mathrm{emu} / \mathrm{g}$ (from the hysteresis cycle).

The magnetic properties of manganese ferrite nanoparticles decorated with gold nanoparticles and core/shell nanostructures show enhanced saturation magnetization relative to that previously determined for $\mathrm{NiFe}_{2} \mathrm{O}_{4} / \mathrm{Au}$ core/shell $\mathrm{NPs}$ or $\mathrm{NiFe}_{2} \mathrm{O}_{4}$ decorated with $\mathrm{Au}[42]$.

\subsection{Drug-Loaded Magnetoliposomes}

Magnetoliposome-type structures were prepared, possessing an octadecylamine (ODA) inner layer and a DPPC lipid outer layer, as previously described [42]. The nanosystems were characterized by DLS in PBS buffer (Table 5), making it possible to observe hydrodynamic diameters below $200 \mathrm{~nm}$ (that are maintained after 7 days), as is requested for an enhanced EPR (Enhanced Permeability and Retention) effect, which allows the extravasation of liposomes and passive targeting [54,55]. TEM images of these nanosystems evidence mainly spherical structures with sizes around $100 \mathrm{~nm}$, although aggregated (Figure 9), in agreement with DLS data. The aggregation observed in TEM images is due to the technique employed, which requires a dry film of the sample in a solid grid and the application of a vacuum. This procedure causes the aggregation of the nanostructures in the grid and, consequently, in TEM images.

Table 5. Hydrodynamic size and polydispersity (PdI) of magnetoliposomes in PBS buffer determined by DLS. (SD: standard deviation).

\begin{tabular}{ccccc}
\hline & \multicolumn{2}{c}{ Size \pm SD (nm) } & \multicolumn{2}{c}{ PdI \pm SD } \\
\cline { 2 - 5 } Type of NPs & $\begin{array}{c}\text { After } \\
\text { Preparation }\end{array}$ & After 7 Days & $\begin{array}{c}\text { After } \\
\text { Preparation }\end{array}$ & After 7 Days \\
\hline $\begin{array}{c}\text { Magnetoliposomes with } \\
\text { decorated NPs }\end{array}$ & $124 \pm 28$ & $136 \pm 34$ & $0.28 \pm 0.08$ & $0.32 \pm 0.062$ \\
\hline $\begin{array}{c}\text { Magnetoliposomes with } \\
\text { core-shell NPs }\end{array}$ & $132 \pm 21$ & $147 \pm 28$ & $0.23 \pm 0.04$ & $0.26 \pm 0.05$ \\
\hline
\end{tabular}

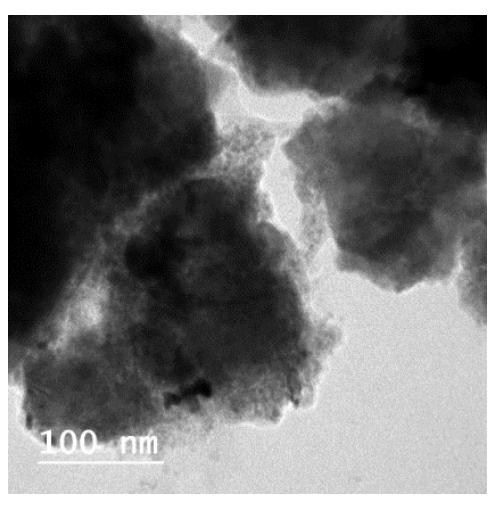

Figure 9. TEM image of magnetoliposomes containing magnetic nanoparticles decorated with gold.

The ability of magnetoliposomes to act as photothermia agents was measured through variations in the absorption spectrum of the lipid probe Nile Red. This molecule was previously shown to have thermochromic behavior [56]. Figures 10A and 11A exhibit absorption spectra of Nile Red when incorporated in magnetoliposomes containing, respectively, core/shell manganese ferrite/gold NPs or gold-decorated manganese ferrite NPs, as a function of the medium temperature. These absorption spectra were acquired in a home-made 
experimental setup that is represented in Scheme 1, using a water bath as a temperature controller. A magnification of the absorption changes is shown in Figures 10B and 11B. For each system, in order to model the variations, the absorption spectra were globally fitted with a sum of eight Gaussian functions, constrained to a sequence of spectral zones and controlled halfwidth (see Supplementary Material and Table S1). The maximum wavelength and halfwidth of each Gaussian function are global parameters of the fit, which are the same for all the temperatures. The weight of each Gaussian function was allowed to vary with temperature, with the three parameters that define such variation also being global parameters for all the temperatures. Additionally, a dispersion contribution with Rayleighlike behavior was considered for each spectrum. A successful fit was obtained, as can be observed in Figures 10A and 11A. The set of global parameters was then used to fit the absorption spectra that result from the irradiation of the same samples (Figures 10C and 11C), using the same experimental setup (Scheme 1). The temperature at each irradiation time is now a local parameter of the global fitting procedure. The obtained local temperatures that result from red light $(\lambda>600 \mathrm{~nm})$ irradiation of the magneto/plasmonic liposomes are shown in Table 6.

Table 6. Local temperature as determined by Nile Red absorption changes.

\begin{tabular}{ccc}
\hline Irradiation Time (min). & $\begin{array}{c}\text { Magnetoliposomes with } \\
\text { Decorated NPs }\end{array}$ & $\begin{array}{c}\text { Magnetoliposomes with } \\
\text { Core/Shell NPs }\end{array}$ \\
\hline 0 & $21^{\circ} \mathrm{C}$ & $21^{\circ} \mathrm{C}$ \\
10 & $21.6^{\circ} \mathrm{C}$ & $21.8^{\circ} \mathrm{C}$ \\
20 & $22.5^{\circ} \mathrm{C}$ & $23.1^{\circ} \mathrm{C}$ \\
30 & $22.8^{\circ} \mathrm{C}$ & $23.8^{\circ} \mathrm{C}$ \\
40 & $22.9^{\circ} \mathrm{C}$ & $23.9^{\circ} \mathrm{C}$ \\
50 & $22.9^{\circ} \mathrm{C}$ & $24.0^{\circ} \mathrm{C}$ \\
\hline
\end{tabular}

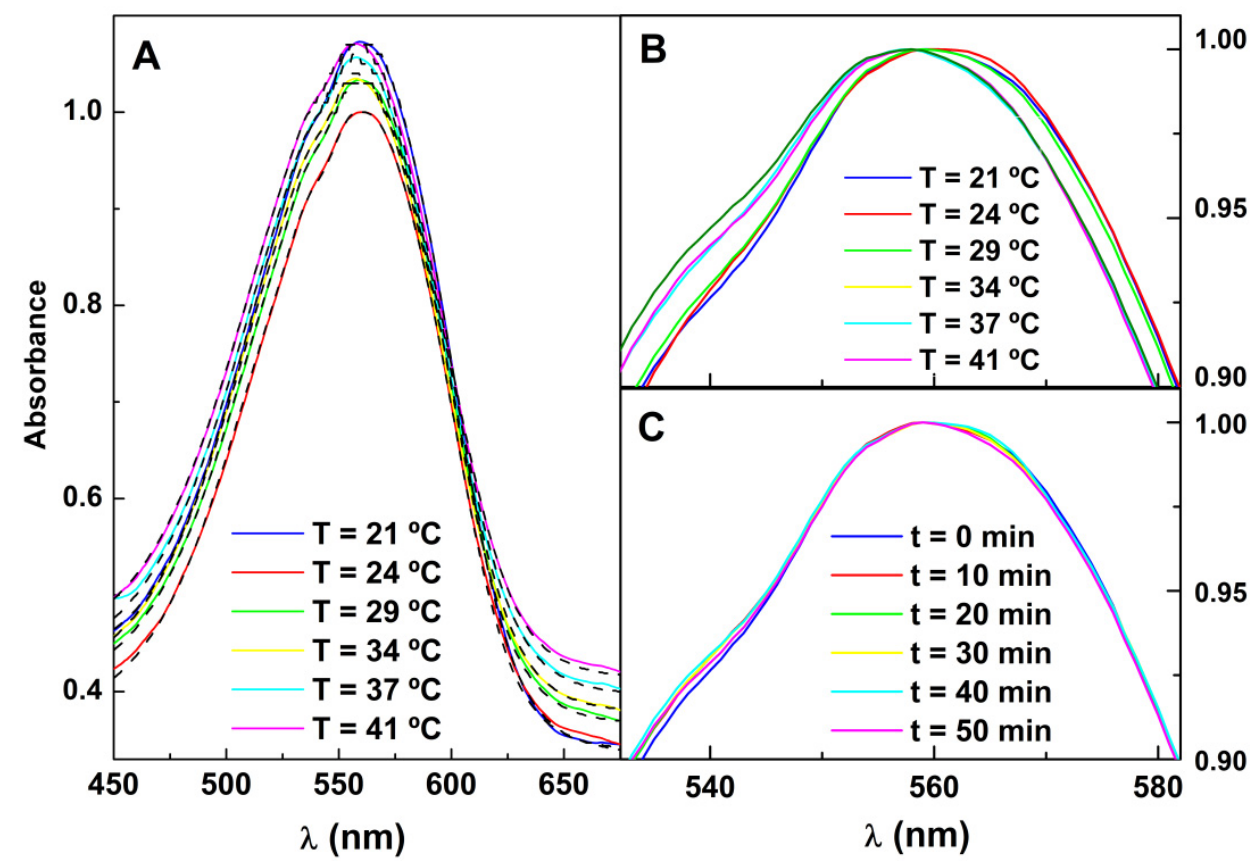

Figure 10. (A) Variation of absorption spectra of Nile Red in magnetoliposomes containing core/shell nanoparticles, at different temperatures and fitting to the model (dashed curves). (B) Expansion of the normalized spectra of Figure A in the maxima region. (C) Expansion of the normalized spectra in the maxima region at several times of irradiation. 


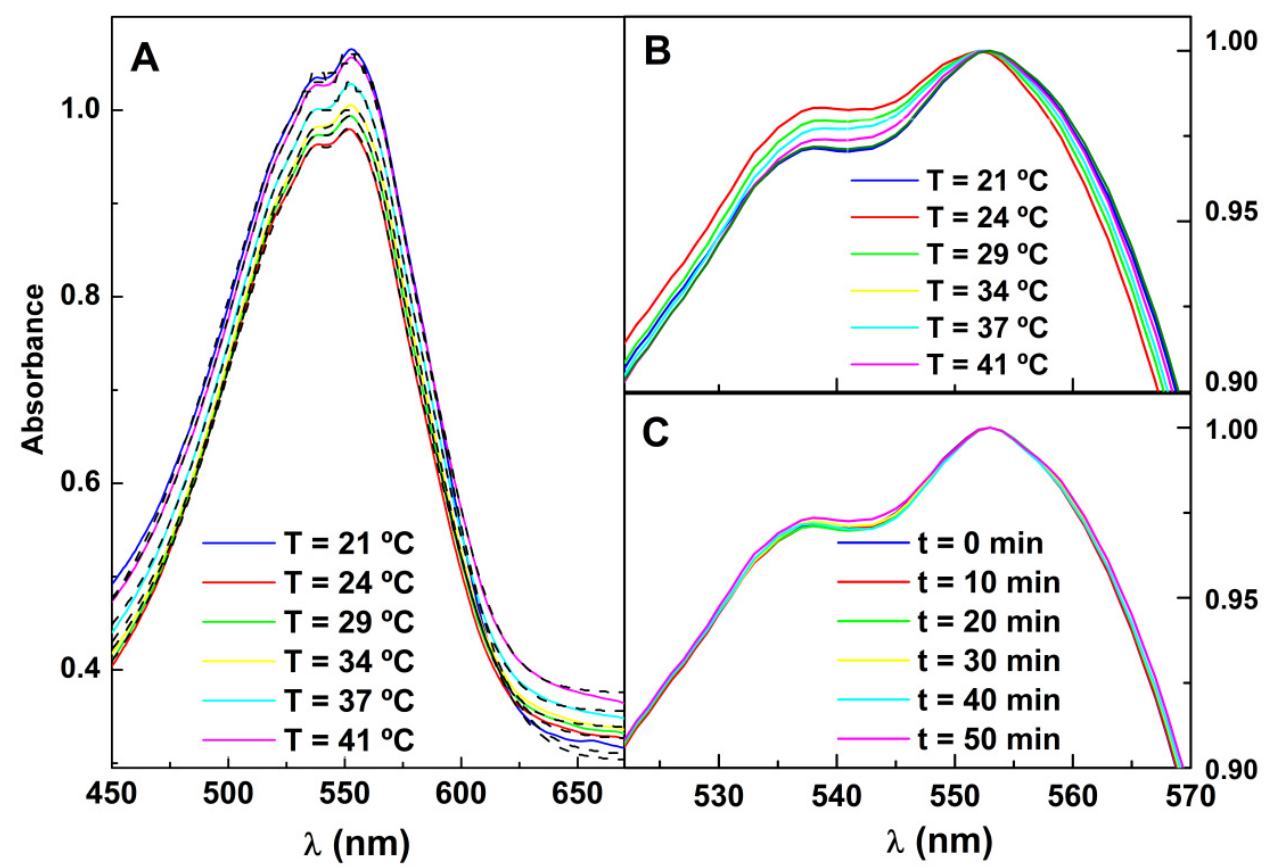

Figure 11. (A) Variation of absorption spectra of Nile Red in magnetoliposomes containing decorated nanoparticles, at different temperatures and fitting to the model (dashed curves). (B) Expansion of the normalized spectra of Figure A in the maxima region. (C) Expansion of the normalized spectra in the maxima region at several times of irradiation.

From Table 6, it is possible to conclude that the core/shell nanoparticles are much more effective in increasing the local temperature than the decorated ones, allowing a local increase of $3{ }^{\circ} \mathrm{C}$. This value is an underestimation, as during the time the absorption spectra were measured, it was necessary to block the irradiation light. This results in heat diffusion into the solvent during the measurement time, as the plasmonic heating sources are no longer active.

The potential of magnetoliposomes as nanocarriers for antitumor compounds $\mathbf{1}$ and $\mathbf{2}$ was assessed. Using the intrinsic fluorescence of the new tricyclic lactones, it is possible to infer the main location of compounds in magnetoliposomes through fluorescence anisotropy measurements. First, considering that compounds are not emissive in aqueous media, the observed fluorescence in magnetoliposomes points to a location in the surfac$\operatorname{tant} /$ lipid bilayer. Moreover, the fluorescence anisotropy values $(r=0.071$ for compound 1 and $\mathrm{r}=0.115$ for compound 2) indicate a deep location in the bilayer, in the fluid region of membrane interior, as anisotropy values are moderate to low.

The drug encapsulation efficiencies were determined for both compounds (Table 7) in magnetoliposomes containing the two types of nanoparticles (decorated or core/shell), also using fluorescence emission. The encapsulation efficiencies are very high, confirming the affinity of both compounds by magnetoliposomes.

Table 7. Encapsulation efficiencies (EE\%) of antitumor compounds $\mathbf{1}$ and 2. SD is the standard deviation of three independent assays.

\begin{tabular}{ccc}
\hline \multirow{2}{*}{ System } & \multicolumn{2}{c}{ EE\% \pm SD\% } \\
\cline { 2 - 3 } & Compound 1 & Compound 2 \\
\hline Magnetoliposomes with core-shell NPs & $99.3 \pm 0.8$ & $99.9 \pm 0.5$ \\
Magnetoliposomes with decorated NPs & $98.5 \pm 1.3$ & $99.8 \pm 0.6$ \\
\hline
\end{tabular}


The interaction with biomembrane models was assessed to infer whether the antitumor compounds can be released from the nanocarriers by fusion with cell membranes. As biomembrane models, Giant Unilamellar Vesicles (GUVs) were used [31,32]. The fusogenic capability was investigated by fluorescence emission. After the interaction of the drugloaded magnetoliposomes with GUVs, a notable fluorescence unquenching (increase in fluorescence emission) is detected for both drugs (Figure 12). This is a result of the increase in distance between the drugs and the magnetic/plasmonic nanoparticles. The latter, when in close proximity to the drugs, absorbs part of the excitation light, producing a decrease in fluorescence emissions of the compounds. Compound 2 seems to present two different locations in the lipid nanosystems, as two bands are present in the fluorescence spectrum (Figure 12B). A small band with a maximum size of approximately $640 \mathrm{~nm}$ may indicate a more hydrated environment (near the lipid head groups).

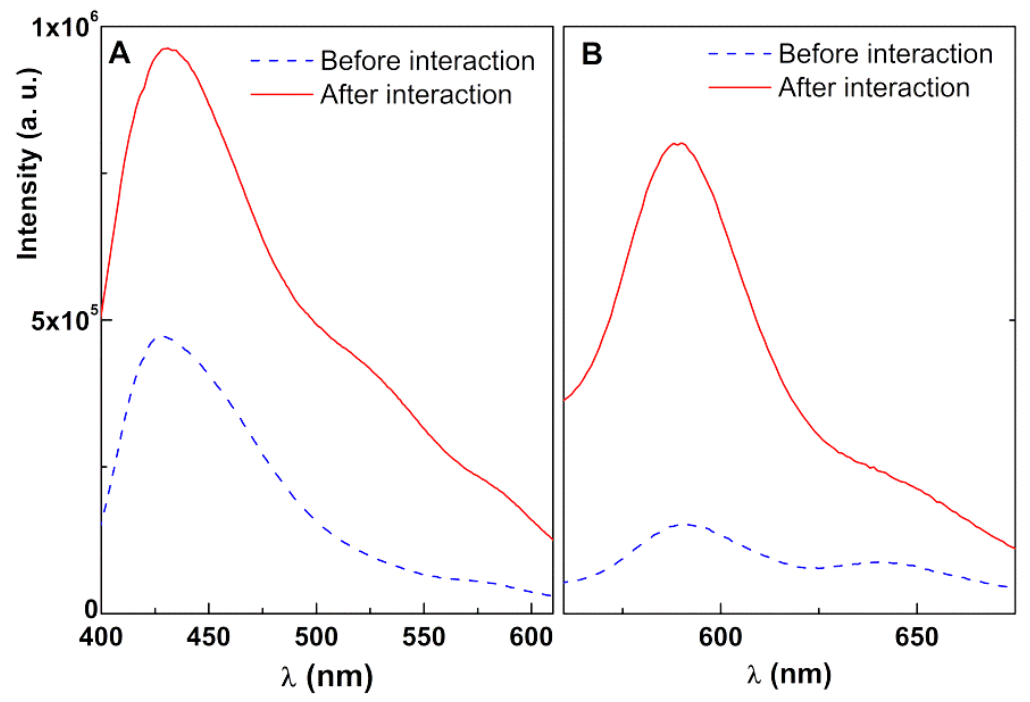

Figure 12. Fluorescence spectra of (A) compound $1\left(\lambda_{\mathrm{exc}}=370 \mathrm{~nm}\right)$ and $(\mathbf{B})$ compound 2 $\left(\lambda_{\text {exc }}=420 \mathrm{~nm}\right)$ in magnetoliposomes before and after interaction with GUVs.

\subsection{Cytotoxicity Assays in Cell Lines}

The biological activity of the developed nanosystem was evaluated in normal (nontumor) and human tumor cell lines. The toxicity studies of the drug-loaded nanocarriers towards non-tumor cells, using porcine liver primary cells (PLP2), were performed under irradiation (Figure 13). No appreciable loss of viability was observed, except for very high concentrations of compound 2 in one of the nanocarriers. These results evidence the biocompatibility of the drug-loaded nanocarriers under irradiation in non-tumor cells. Hence, it must be emphasized that the local rise in temperature seems to be insufficient to kill non-tumor cells.

Among the deadliest cancer types are, in descending order, the cancers of the lungs, prostate, and colorectal cancer in men and the lungs, breast, and colorectal cancer in women [1]. These facts led us to investigate the growth inhibitory activity of the drugloaded nanocarriers in human NCI-H460 cell lines (non-small-cell lung cancer). As previously mentioned, both compounds exhibit promising antitumor activity for this type of cancer cells (Table 1). The assays in the NCI-H460 cell line were carried out in the presence and absence of irradiation to determine the effective photothermia capability of the developed nanosystems. In the absence of irradiation, no loss of viability was observed in tumor cell lines (Figure 14), even at very high compound concentrations, showing that the antitumor compounds are not released in the absence of the local temperature rise promoted by the plasmonic effect of gold. On the contrary, when irradiation with light was applied, notable growth-inhibitory activity was observed in tumor cells for the nanocarriers containing the core/shell nanoparticles. The $\mathrm{GI}_{50}$ values (the concentration of 
which inhibited $50 \%$ of the cell growth) are very low, with values around $100 \mathrm{nM}$ (Table 8). The $\mathrm{GI}_{50}$ is slightly lower for the more active antitumor compound (compound $\mathbf{1}$ ). This clearly demonstrates the synergistic effect between photothermia and drug cytotoxicity to tumor cells, enhancing the antitumor activity by the local rise in temperature promoted by the plasmonic effect of gold. On the other hand, for the nanosystems containing the magnetic nanoparticles decorated with gold, the growth inhibition of $50 \%$ of tumor cells was not attained. Moreover, the decorated nanoparticles seem not to have enough quantity of gold for photothermia-triggered drug release. This is in accordance with the previously reported incomplete covering of nickel ferrite nanoparticles with gold in the decorated magnetic/plasmonic NPs [42].

Overall, these results demonstrate that the drug-loaded magnetoliposomes with coreshell nanoparticles are suitable for a light-triggered release in non-small cell lung cancer, because (i) no cell viability loss was observed in normal cells (under irradiation), and (ii) in NCI-H460 tumor cells, the nanosystem only showed growth inhibitory activity in the presence of irradiation. These results anticipate the promising application of these nanosystems in non-small-cell lung cancer treatment, using irradiation as a trigger for drug release.
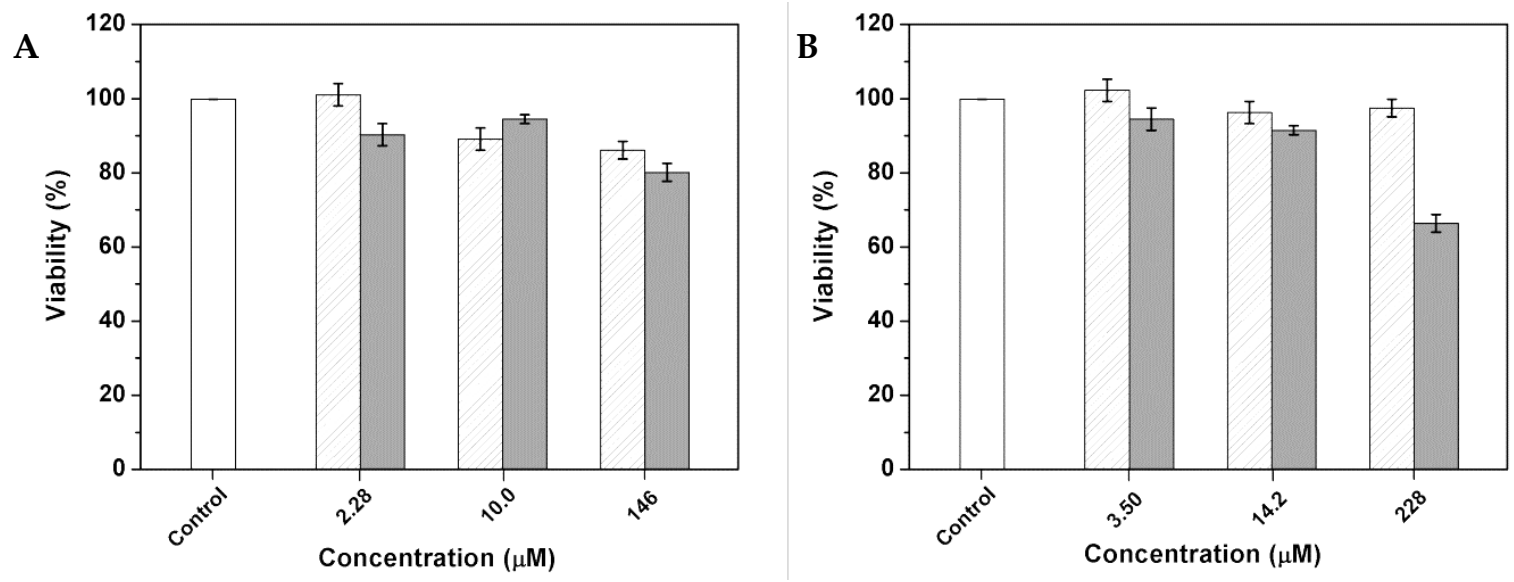

Figure 13. Viability of PLP2 cells exposed to drug-loaded nanocarriers based on $\mathrm{MnFe}_{2} \mathrm{O}_{4} / \mathrm{Au}$ core/shell NPs (dashed column) and nanocarriers based on $\mathrm{MnFe}_{2} \mathrm{O}_{4}$ decorated with $\mathrm{Au}$ (grey column), under irradiation. (A) Compound 1; (B) Compound 2 .
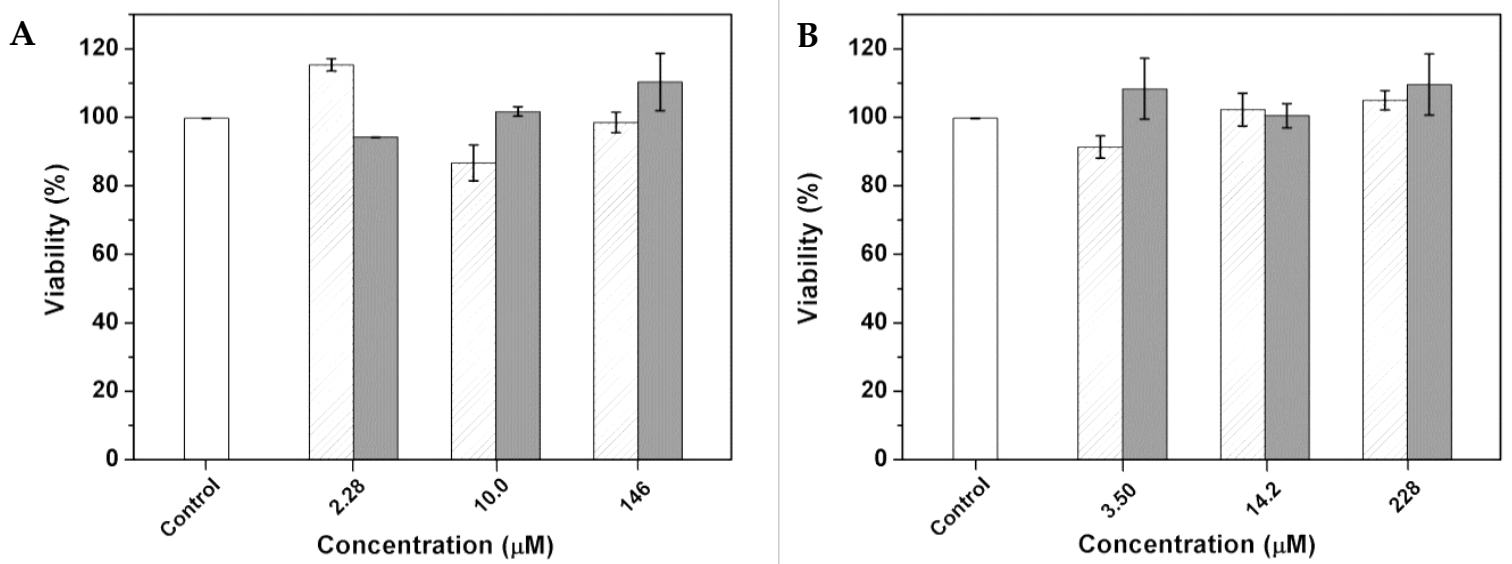

Figure 14. Viability of NCI-H460 tumor cells exposed to drug-loaded nanocarriers containing $\mathrm{MnFe}_{2} \mathrm{O}_{4} / \mathrm{Au}$ core/shell NPs (dashed column) and containing $\mathrm{MnFe}_{2} \mathrm{O}_{4}$ decorated with Au NPs (grey column), without irradiation. (A) Compound 1; (B) Compound 2. 
Table 8. Growth inhibitory concentrations $\left(\mathrm{GI}_{50}\right)$ in NCI-H460 lung cancer cell line. The results are from three independent experiments (performed in triplicate) and are expressed as mean \pm standard deviation (SD).

\begin{tabular}{ccc}
\hline System & \multicolumn{2}{c}{ GI $_{\mathbf{5 0}} \pm \mathrm{SD}(\boldsymbol{\mu M})$} \\
\cline { 2 - 3 } & Compound 1 & Compound 2 \\
\hline $\begin{array}{c}\text { Drug-loaded magnetoliposomes } \\
\text { with decorated NPs } \\
\text { Drug-loaded magnetoliposomes } \\
\text { with core-shell NPs }\end{array}$ & - & - \\
\hline
\end{tabular}

\section{Conclusions}

Nanoparticles consisting of $\mathrm{MnFe}_{2} \mathrm{O}_{4}$ magnetic nanoparticles either decorated with plasmonic gold nanoparticles or covered by a plasmonic gold shell were successfully obtained. A surfactant/lipid (ODA/DPPC) bilayer was used to wrap up these nanoparticles, leading to the synthesis of a liposome-like structure. The nanosystems were loaded with two new potential antitumor tricyclic lactones. The drug-loaded nanosystems exhibited hydrodynamic sizes below $200 \mathrm{~nm}$, high encapsulation efficiencies, and a fusogenic capability with model membranes. The drug-loaded magnetoliposomes containing $\mathrm{MnFe}_{2} \mathrm{O}_{4}$ /gold core/shell nanoparticles were shown to be promising in future applications in dual cancer therapy, combining photothermia and chemotherapy.

Supplementary Materials: The following are available online at https:/ /www.mdpi.com/article/ 10.3390/pharmaceutics13111905/s1: Modeling of Nile Red absorption spectra, Table S1. Gaussian functions parameters. Photophysical stability of compound solutions, Figure S1. Fluorescence emission spectra of compound 1 in chloroform (A) and ethanol (B) (as examples), immediately after solution preparation and after 1 and 3 months of storage; Figure S2. Fluorescence emission spectra of compound 2 in ethyl acetate (A) and acetonitrile (B) (as examples), immediately after solution preparation and after 1 and 3 months of storage. TEM/STEM images and EDS analysis, Figure S3. (A) Transmission Electron Microscopy image of core/shell nanoparticles and (B) corresponding histogram. (C) Transmission Electron Microscopy image of decorated nanoparticles and (D) corresponding histogram. (E) Expansion of image $\mathrm{C}$ (white square) and (F) corresponding histogram; Figure S4. (A) and (B) Scanning electron microscopy images in transmission mode (STEM) of core/shell nanoparticles. (C) EDS spectrum of region Z1 (red square) from figure (A). (D) TLD image.

Author Contributions: Conceptualization, E.M.S.C. and P.J.G.C.; methodology, E.M.S.C., M.-J.R.P.Q., I.C.F.R.F. and P.J.G.C.; validation, A.R.O.R., J.M.R., B.G.A., A.M.P., J.P.A., R.C.C. and P.J.G.C.; formal analysis, I.S.R.R., A.R.O.R., B.G.A.; A.P.; A.M.P., J.P.A., R.C.C., and E.M.S.C.; investigation, I.S.R.R., A.R.O.R., J.M.R., R.C.C. and A.P.; writing-original draft preparation, I.S.R.R., E.M.S.C. and P.J.G.C.; writing—review and editing, E.M.S.C., M.-J.R.P.Q. and P.J.G.C.; supervision, E.M.S.C., M.-J.R.P.Q., I.C.F.R.F. and P.J.G.C.; project administration, P.J.G.C. All authors have read and agreed to the published version of the manuscript.

Funding: This research was funded by the Portuguese Foundation for Science and Technology (FCT) in the framework of the Strategic Funding of CF-UM-UP (UIDB/04650/2020) and through the research project PTDC/QUI-QFI/28020/2017 (POCI-01-0145-FEDER-028020), financed by the European Fund of Regional Development (FEDER), COMPETE2020, and Portugal2020. I.S.R.R. acknowledges FCT for a research grant under CF-UM-UP Strategic Funding (UID/FIS/04650/2019) and a PhD grant (2020.04431.BD). J.M.R. acknowledges FCT, ESF (European Social Fund-North Portugal Regional Operational Program) and HCOP (Human Capital Operational Program) for a PhD grant (SFRH/BD/115844/2016). The APC was also financed by FCT.

Institutional Review Board Statement: Not applicable.

Informed Consent Statement: Not applicable.

Data Availability Statement: Not applicable. 
Acknowledgments: The authors acknowledge the Centre for Biological Engineering (CEB) of the University of Minho for the availability of DLS equipment.

Conflicts of Interest: The authors declare no conflict of interest.

\section{References}

1. Siegel, R.L.; Miller, K.D.; Jemal, A. Cancer statistics, 2019. CA Cancer J. Clin. 2019, 69, 7-34. [CrossRef]

2. Bremer-Hoffmann, S.; Amenta, V.; Rossi, F. Nanomedicines in the European translational process. Eur. J. Nanomed. 2015, 7, 191-202. [CrossRef]

3. Chang, E.H.; Harford, J.B.; Eatin, M.A.; Boisseau, P.M.; Dube, A.; Hayeshi, R.; Swai, H.; Lee, D.S. Nanomedicine: Past, present and future-A global perspective. Biochem. Biophys. Res. Commun. 2015, 468, 511-517. [CrossRef]

4. Gurunathan, S.; Kang, M.H.; Qasim, M.; Kim, J.H. Nanoparticle-Mediated Combination Therapy: Two-in-One Approach for Cancer. Int. J. Mol. Sci. 2018, 19, 3264. [CrossRef]

5. Wang, J.; Hu, X.; Xiang, D. Nanoparticles drug delivery systems: An excellent carrier for tumor peptide vaccines. Drug Deliv. 2018, 25, 1319-1327. [CrossRef]

6. Deshpande, P.P.; Biswas, S.; Torchilin, V.P. Current trends in the use of liposomes for tumor targeting. Nanomedicine (Lond.) 2013, 8, 1509-1528. [CrossRef]

7. Gobbo, O.L.; Sjaatsad, K.; Radomski, M.K.; Volkov, Y.; Prina-Mello, A. Magnetic nanoparticles in cancer theranostics. Theranostics 2015, 5, 1249-1263. [CrossRef]

8. Datta, N.R.; Krishnan, S.; Speiser, D.E.; Neufeld, E.; Kuster, N.; Bodis, S.; Hofmann, H. Magnetic nanoparticle-induced hyperthermia with appropriate payloads: Paul Ehrlich's "magic (nano)bullet" for cancer theranostics? Cancer Treat. Rev. 2016, 50, 217-227. [CrossRef]

9. Issa, B.; Obaidat, I.M.; Albiss, B.A.; Haik, Y. Magnetic nanoparticles: Surface effects and properties related to biomedicine applications. Int. J. Mol. Sci. 2013, 14, 21266-21305. [CrossRef]

10. Pereira, C.; Pereira, A.M.; Fernandes, C.; Rocha, M.; Mendes, R.; Garcia, M.P.F.; Guedes, A.; Tavares, P.B.; Grenèche, J.M.; Araújo, J.P.; et al. Superparamagnetic $\mathrm{MFe}_{2} \mathrm{O}_{4}(\mathrm{M}=\mathrm{Fe}, \mathrm{Co}, \mathrm{Mn})$ nanoparticles: Tuning the particle size and magnetic properties through a novel one-step coprecipitation route. Chem. Mater. 2012, 24, 1496-1504. [CrossRef]

11. Cabrera, L.I.; Somoza, A.; Marco, J.F.; Serna, C.J.; Morales, M.P. Synthesis and surface modification of uniform $\mathrm{MFe}_{2} \mathrm{O}_{4}(\mathrm{M}=\mathrm{Fe}$, Mn, and Co) nanoparticles with tunable sizes and functionalities. J. Nanopart. Res. 2012, 14, 873. [CrossRef]

12. Colombo, M.; Carregal-Romero, S.; Casula, M.F.; Gutiérrez, L.; Morales, M.P.; Böhm, I.B.; Heverhagen, J.T.; Prosperi, D.; Parak, W.J. Biological applications of magnetic nanoparticles. Chem. Soc. Rev. 2012, 41, 4306-4334. [CrossRef]

13. Rahman, M.; Ahmad, M.Z.; Kazmi, I.; Akhter, S.; Afzal, M.; Gupta, G.; Sinha, V.R. Emergence of Nanomedicine as cancer-targeted magic bullets: Recent development and need to address the toxicity apprehension. Curr. Drug Discov. Technol. 2012, 9, 319-329. [CrossRef] [PubMed]

14. Kafrouni, L.; Savadogo, O. Recent progress on magnetic nanoparticles for magnetic hyperthermia. Prog. Biomater. 2016, 5, 147-160. [CrossRef]

15. Sood, A.; Arora, V.; Shah, J.; Kotnala, R.K.; Jain, T.K. Multifunctional gold coated iron oxide core-shell nanoparticles stabilized using thiolated sodium alginate for biomedical applications. Mater. Sci. Eng. C 2017, 80, 274-281. [CrossRef]

16. Das, M.; Shim, K.; An, S.; Yi, D. Review on gold nanoparticles and their applications. Toxicol. Environ. Health Sci. $2011,3,193-205$. [CrossRef]

17. Yeh, Y.; Creran, B.; Rotello, V. Gold nanoparticles: Preparation, properties, and applications in bionanotechnology. Nanoscale 2012, 4, 1871-1880. [CrossRef]

18. Carneiro, M.H.; Barbosa, F. Gold nanoparticles: A critical review of therapeutic applications and toxicological aspects. J. Toxicol Environ. Health B 2016, 19, 129-148. [CrossRef]

19. Huang, X.; El-Sayed, M.A. Gold nanoparticles: Optical properties and implementations in cancer diagnosis and photothermal therapy. J. Adv. Res. 2010, 1, 13-28. [CrossRef]

20. Stockman, M. Nanoplasmonics: The physics behind the applications. Phys. Today 2011, 64, 39-44. [CrossRef]

21. Amendola, V.; Pilot, R.; Frasconi, M.; Maragò, O.; Iatì, M. Surface plasmon resonance in gold nanoparticles: A review. J. Phys. Condens. Matter 2017, 29, 203002. [CrossRef]

22. Singh, P.; Pandit, S.; Mokkapati, V.; Garg, A.; Ravikumar, V.; Mijakovic, I. Gold nanoparticles in diagnostics and therapeutics for human cancer. Int. J. Mol. Sci. 2018, 19, 1979. [CrossRef]

23. Larsen, G.K.; Farr, W.; Murph, S.E.H. Multifunctional $\mathrm{Fe}_{2} \mathrm{O}_{3}-\mathrm{Au}$ nanoparticles with different shapes: Enhanced catalysis, photothermal effects, and magnetic recyclability. J. Phys. Chem. C 2016, 120, 15162-15172. [CrossRef]

24. Stafford, S.; Garcia, R.S.; Gun'ku, Y.K. Multimodal magnetic-plasmonic nanoparticles for biomedical applications. Appl. Sci. 2018, 8, 97. [CrossRef]

25. Espinosa, A.; Reguera, J.; Curcio, A.; Muñoz-Noval, A.; Kuttner, C.; Van de Walle, A.; Liz-Marzán, L.M.; Wilhelm, C. Janus Magnetic-Plasmonic Nanoparticles for Magnetically Guided and Thermally Activated Cancer Therapy. Small 2020, 16, 1904960. [CrossRef] [PubMed]

26. Queiroz, M.-J.R.P.; Calhelha, R.C.; Vale-Silva, L.; Pinto, E.; Nascimento, M.S.-J. Novel [6-(hetero)arylamino]thieno [3,2- $b$ ]pyridines: Synthesis and antitumoral activities. Eur. J. Med. Chem. 2010, 45, 5732-5738. [CrossRef] 
27. Machado, V.A.; Peixoto, D.R.; Costa, H.J.C.; Froufe, R.C.; Calhelha, R.M.V.; Abreu, I.C.F.R.; Ferreira, R.; Soares, M.-J.R.P. Queiroz, Synthesis, antiangiogenesis evaluation and molecular docking studies of 1-aryl-3-[(thieno[3,2-b]pyridin-7-ylthio)phenyl]ureas: Discovery of a new substitution pattern for type II VEGFR-2 Tyr kinase inhibitors. Bioorg. Med. Chem. 2015, 23, 6497-6509. [CrossRef]

28. Rodrigues, J.M.; Buisson, P.; Pereira, J.M.; Pinheiro, I.M.; Fernández-Marcelo, T.; Vasconcelos, M.H.; Berteina-Raboin, S.; Queiroz, M.-J.R.P. Synthesis of novel 8-(het)aryl-6H-pyrano[ $\left.4^{\prime}, 3^{\prime}: 4,5\right]$ thieno[3,2-b] pyridines by 6-endo-dig cyclization of Sonogashira products and halolactonizations with Cu salts/NXS. Preliminary antitumor evaluation. Tetrahedron 2019, 75, 1387-1397. [CrossRef]

29. Brust, M.; Walker, M.; Bethell, D.; Schiffrin, D.J.; Whyman, R. Synthesis of thiol-derivatised gold nanoparticles in a two-phase liquid-liquid system. J. Chem. Soc. Chem. Commun. 1994, 7, 801-802. [CrossRef]

30. Brown, K.R.; Natan, M.J. Hydroxylamine seeding of colloidal Au nanoparticles in solution and on surfaces. Langmuir 1998, 14, 726-728. [CrossRef]

31. Tamba, Y.; Terashima, H.; Yamazaki, M. A membrane filtering method for the purification of giant unilamellar vesicles. Chem. Phys. Lipids 2011, 164, 351-358. [CrossRef] [PubMed]

32. Tanaka, T.; Tamba, Y.; Masum, S.M.; Yamashita, Y.; Yamazaki, M. La ${ }^{3+}$ and Gd ${ }^{3+}$ induce shape change of giant unilamellar vesicles of phosphatidylcholine. Biochim. Biophys. Acta 2002, 1564, 173-182. [CrossRef]

33. Dias, M.I.; Barros, L.; Dueñas, M.; Pereira, E.; Carvalho, A.M.; Alves, R.C.; Oliveira, M.B.P.P.; Santos-Buelga, C.; Ferreira, I.C.F.R Chemical composition of wild and commercial Achillea millefolium L. and bioactivity of the methanolic extract, infusion and decoction. Food Chem. 2013, 141, 4152-4160. [CrossRef] [PubMed]

34. Vichai, V.; Kirtikara, K. Sulforhodamine B colorimetric assay for cytotoxicity screening. Nat. Protoc. 2006, 1, 1112-1116. [CrossRef] [PubMed]

35. Magalhães, A.F.; Graça, V.C.; Calhelha, R.C.; Ferreira, I.C.F.R.; Santos, P.F. Aminosquaraines as potential photodynamic agents: Synthesis and evaluation of in vitro cytotoxicity. Bioorg. Med. Chem. Lett. 2017, 27, 4467-4470. [CrossRef] [PubMed]

36. Queiroz, M.-J.R.P.; Peixoto, D.; Rodrigues, A.R.O.; Mendes, P.M.F.; Costa, C.N.C.; Coutinho, P.J.G.; Castanheira, E.M.S. New 1,3-diarylureas linked by C-C Suzuki coupling to the methyl 3-aminothieno[3,2-b]pyridine-2-carboxylate moiety: Synthesis and fluorescence studies in solution and in lipid membranes. J. Photochem. Photobiol. A Chem. 2013, 255, 27-35. [CrossRef]

37. Costa, C.N.C.; Hortelão, A.C.L.; Ramos, J.M.F.; Oliveira, A.D.S.; Calhelha, R.C.; Queiroz, M.-J.R.P.; Coutinho, P.J.G.; Castanheira, E.M.S. A new antitumoral heteroarylaminothieno[3,2-b]pyridine derivative: Its incorporation into liposomes and interaction with proteins monitored by fluorescence. Photochem. Photobiol. Sci. 2014, 13, 1730-1740. [CrossRef]

38. Rodrigues, A.R.O.; Almeida, B.G.; Rodrigues, J.M.; Queiroz, M.J.R.P.; Calhelha, R.C.; Ferreira, I.C.F.R.; Pires, A.; Pereira, A.M.; Araújo, J.P.; Coutinho, P.J.G.; et al. Magnetoliposomes as carriers for promising antitumor thieno[3,2-b]pyridin-7-arylamines: Photophysical and biological studies. RSC Adv. 2017, 7, 15352-15361. [CrossRef]

39. Rodrigues, A.R.O.; Ramos, J.M.F.; Gomes, I.T.; Almeida, B.G.; Araújo, J.P.; Queiroz, M.-J.R.P.; Coutinho, P.J.G.; Castanheira, E.M.S. Magnetoliposomes based on manganese ferrite nanoparticles as nanocarriers for antitumor drugs. RSC Adv. 2016, 6, 17302-17313. [CrossRef]

40. Fink, J.; Kiely, C.J.; Bethell, D.; Schiffrin, D.J. Self-Organization of Nanosized Gold Particles. Chem. Mater. 1998, 10, 922-926. [CrossRef]

41. Rodrigues, A.R.O.; Matos, J.O.G.; Nova Dias, A.M.; Almeida, B.G.; Pires, A.; Pereira, A.M.; Araújo, J.P.; Queiroz, M.J.R.P.; Castanheira, E.M.S.; Coutinho, P.J.G. Development of multifunctional liposomes containing magnetic/ $\mathrm{plasmonic} \mathrm{MnFe}_{2} \mathrm{O}_{4} / \mathrm{Au}$ core/shell nanoparticles. Pharmaceutics 2019, 11, 10. [CrossRef]

42. Rio, I.S.R.; Rodrigues, A.R.O.; Rodrigues, C.P.; Almeida, B.G.; Pires, A.; Pereira, A.M.; Araújo, J.P.; Castanheira, E.M.S.; Coutinho, P.J.G. Development of novel magnetoliposomes containing nickel ferrite nanoparticles covered with gold for applications in thermotherapy. Materials 2020, 13, 815. [CrossRef]

43. Wu, D.; Xu, X.; Liu, X. Influence of dielectric core, embedding medium and size on the optical properties of gold nanoshells. Solid State Commun. 2008, 146, 7-11. [CrossRef]

44. Qian, X.; Bai, J. Theoretical Studies of the Optical Properties of Hollow Spherical Metallic Nanoshells. J. Comput. Theor. Nanosci. 2013, 10, 2354-2360. [CrossRef]

45. Li, R.; Gu, X.; Liang, X.; Hou, S.; Hu, D. Aggregation of Gold Nanoparticles Caused in Two Different Ways Involved in 4-Mercaptophenylboronic Acid and Hydrogen Peroxide. Materials 2019, 12, 1802. [CrossRef] [PubMed]

46. Bergmann, J.; Friedel, P.; Kleeberg, R. Commission on Powder Diffraction Newsletter; Oak Ridge National Laboratory: Oak Ridge, TN, USA, 1998; pp. 5-8.

47. Döbelin, N.; Kleeberg, R. Profex: A graphical user interface for the Rietveld refinement program BGMN. J. Appl. Crystallog. 2015, 48, 1573-1580. [CrossRef] [PubMed]

48. Carta, D.; Casula, M.F.; Falqui, A.; Loche, D.; Mountjoy, G.; Sangregorio, C.; Corrias, A. A structural and magnetic investigation of the inversion degree in ferrite nanocrystals $\mathrm{MFe}_{2} \mathrm{O}_{4}(\mathrm{M}=\mathrm{Mn}, \mathrm{Co}, \mathrm{Ni})$. J. Phys. Chem. C 2009, 113, 8606-8615. [CrossRef]

49. Veloso, S.R.S.; Martins, J.A.; Hilliou, L.; Amorim, C.O.; Amaral, V.S.; Almeida, B.G.; Jervis, P.J.; Moreira, R.; Pereira, D.M.; Coutinho, P.J.G.; et al. Dehydropeptide-based plasmonic magnetogels: A supramolecular composite nanosystem for multimodal cancer therapy. J. Mater. Chem. B 2020, 8, 45-64. [CrossRef] [PubMed] 
50. Nair, S.S.; John, S.A.; Sagara, T. Simultaneous Determination of Paracetamol and Ascorbic Acid Using Tetraoctylammonium Bromide Capped Gold Nanoparticles Immobilized on 1,6-Hexanedithiol Modified Au Electrode. Electrochim. Acta 2009, 54, 6837-6843. [CrossRef]

51. Crespo, P.; Litrán, R.; Rojas, T.C.; Multigner, M.; Fuente, J.M.; Sanchez-Lopez, J.C.; García, M.A.; Hernando, A.; Penades, S.; Fernández, A. Permanent magnetism, magnetic anisotropy, and hysteresis of thiol-capped gold nanoparticles. Phys. Rev. Lett. 2004, 93, 087204. [CrossRef] [PubMed]

52. Smit, J. Magnetic Properties of Materials; McGraw Hill: New York, NY, USA, 1971; p. 89. ISBN 978-0070584457.

53. Chen, J.P.; Sorensen, C.M.; Klabunde, K.J.; Hadjipanayis, G.C.; Devlin, E.; Kostikas, A. Size-dependent magnetic properties of $\mathrm{MnFe}_{2} \mathrm{O}_{4}$ fine particles synthesized by coprecipitation. Phys. Rev. B Condens. Matter 1996, 54, 9288-9296. [CrossRef] [PubMed]

54. Danhier, F.; Feron, O.; Préat, V. To exploit the tumor microenvironment: Passive and active tumor targeting of nanocarriers for anticancer drug delivery. J. Control. Release 2010, 148, 135-146. [CrossRef] [PubMed]

55. Sawant, R.R.; Torchilin, V.P. Challenges in development of targeted liposomal therapeutics. AAPS J. 2012, 14, 303-315. [CrossRef] [PubMed]

56. Kawski, A.; Kukliński, B.; Bojarski, P. Photophysical Properties and Thermochromic Shifts of Electronic Spectra of Nile Red in Selected Solvents. Excited States Dipole Moments. Chem. Phys. 2009, 359, 58-64. [CrossRef] 